\title{
WAVE REFLECTION FROM NATURAL BEACHES
}

\author{
by \\ Todd L. Walton, Jr. \\ Coastal Engineering Research Center \\ DEPARTMENT OF THE ARMY
}

Waterways Experiment Station, Corps of Engineers

3909 Halls Ferry Road, Vicksburg, Mississippi 39180-6199
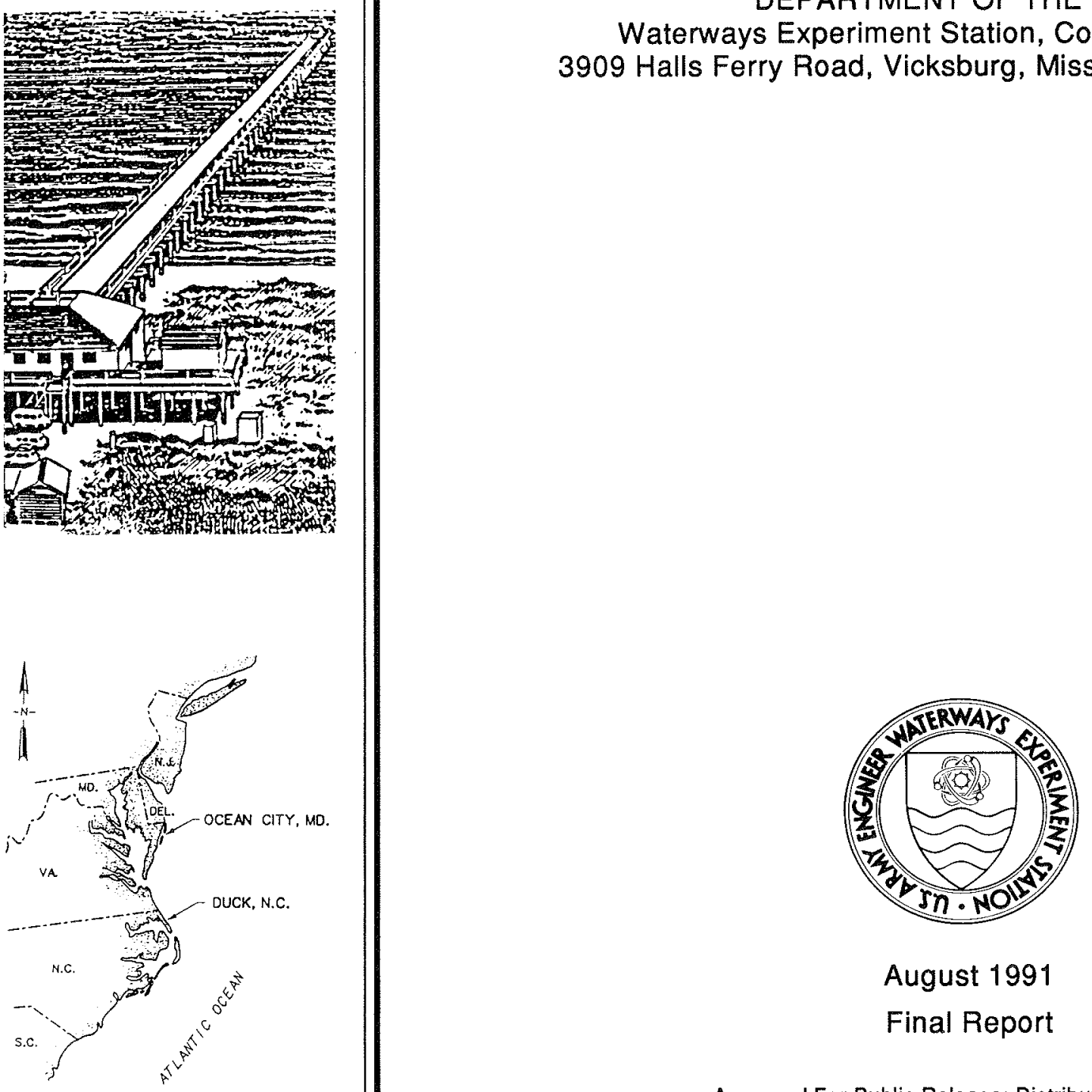

August 1991

Final Report

Approved For Public Release; Distribution Unlimited

Prepared for DEPARTMENT OF THE ARMY

US Army Corps of Engineers

Washington, DC 20314-1000

Under Civil Works Research Work Unit 32531 
Destroy this report when no longer needed. Do not return it to the originator.

The findings in this report are not to be construed as an official Department of the Army position unless so designated by other authorized documents.

The contents of this report are not to be used for advertising, publication, or promotional purposes. Citation of trade names does not constitute an official endorsement or approval of the use of such commercial products. 
Public reporting burden for this collection of information is estimated to average i hour per response, including the time for reviewing instructions, searching existing data sources. gathering and maintaining the data needed, and completing and revrewing the collection of information. Send comments regarding this burden estimate of any other aspect of this collection of information, including suggestions for reducing this burden, to Washington Headquarters services, Directorate for information Operations and Reports, 1215 Jefferson Davis Highway, Suite 1204, Aflington, VA 22202-4302, and to the Office of Management and Budget, Paperwork Reduction Project (0704.0188), Washington, DC 20503.

\begin{tabular}{|c|c|c|}
\hline 1. AGENCY USE ONLY (Leave blank) & $\begin{array}{l}\text { 2. REPORT OATE } \\
\text { August } 1991\end{array}$ & $\begin{array}{l}\text { 3. REPORT TYPE AND DATES COVERED } \\
\text { Einal report }\end{array}$ \\
\hline
\end{tabular}

\section{TITLE AND SUBTITLE}

August 1991

5. FUNDING NUMBERS

Wave Reflection from Natural Beaches

Todd I. Walton, Jr.

7. PERFORMING ORGANIZATION NAME(S) AND ADDRESS(ES)

USAE Waterways Experiment Station

Coastal Engineering Research Center

3909 Halls Eerry Road

Vicksburg, MS 39180-6199

9. SPONSORING/MONITORING AGENCY NAMAE(S) AND ADDRESS(ES)

US Army Corps of Engineers

Washington, DC 20314-1000

\section{B. PERFORMING ORGANIZATION} REPORT NUMBER

Miscellaneous Paper CERC-91-9

10. SPONSORING/MONITORING AGENCY REPORT NUMBER

\section{SUPPLEMENTARY NOTES}

Available from National Technical Information Service, 5285 Port Royal Road, Springfield, VA 22161

Approved for public release; distribution unlimited

\section{ABSTRACT (Maximum 200 word's)}

Wave reflection from natural beaches is discussed and computed for two sites on the Atlantic coast of the United States. Data for computational purposes consist of near-bottom mounted pressure sensor measurements and coincident electromagnetic current meter orthogonal velocities. The procedure used for computation of wave reflection utilizes a signal separation approach consistent with linear theory. Results of analysis show low wave reflection for the cases considered.

14. SUBJECT TERMS
Linear wave theOIY
Natural beaches
$\begin{array}{ll}\text { 17. SECURITY CLASSIFICATION } \\ \text { OF REPORT }\end{array}$
$\begin{aligned} & \text { UNCLASS IFIED } \\ & \text { OFCURITY CLASSIFICATION } \\ & \text { UNCLASS IEIED }\end{aligned}$

19. SECURITY CLASSIFICATION OF ABSTRACT
15. NUMBER OF PAGES 42

16. PRICE CODE 
The study summarized in this report was authorized by the Headquarters, US Army Corps of Engineers (HQUSACE). Research was conducted under Work Unit 32531, "Irregular Wave Runup," Dr. Todd L. Walton, Jr., Principal Investigator. Funds were provided through the Engineering Development Division (EDD), Coastal Engineering Research Center (CERC), US Army Engineer Waterways Experiment Station (UES), Vicksburg, MS. The HQUSACE Technical Monitors were Messrs. John H. Lockhart, Jr.; John G. Housley; James E. Crews; and Robert H. Campbe11.

Work was performed under the general supervision of Mr. Thomas W. Richardson, Chief, EDD; Dr. C. Linwood Vincent, Program Manager, CERC; Mr. Charles C. Calhoun, Jr., Assistant Chief, CERC; and Dr. James R. Houston, Chief, CERC.

COL Larry B. Fulton, EN, was Commander and Director of WES during the publication of this report. Dr. Robert W. Whalin was Technical Director. 
CONTENTS

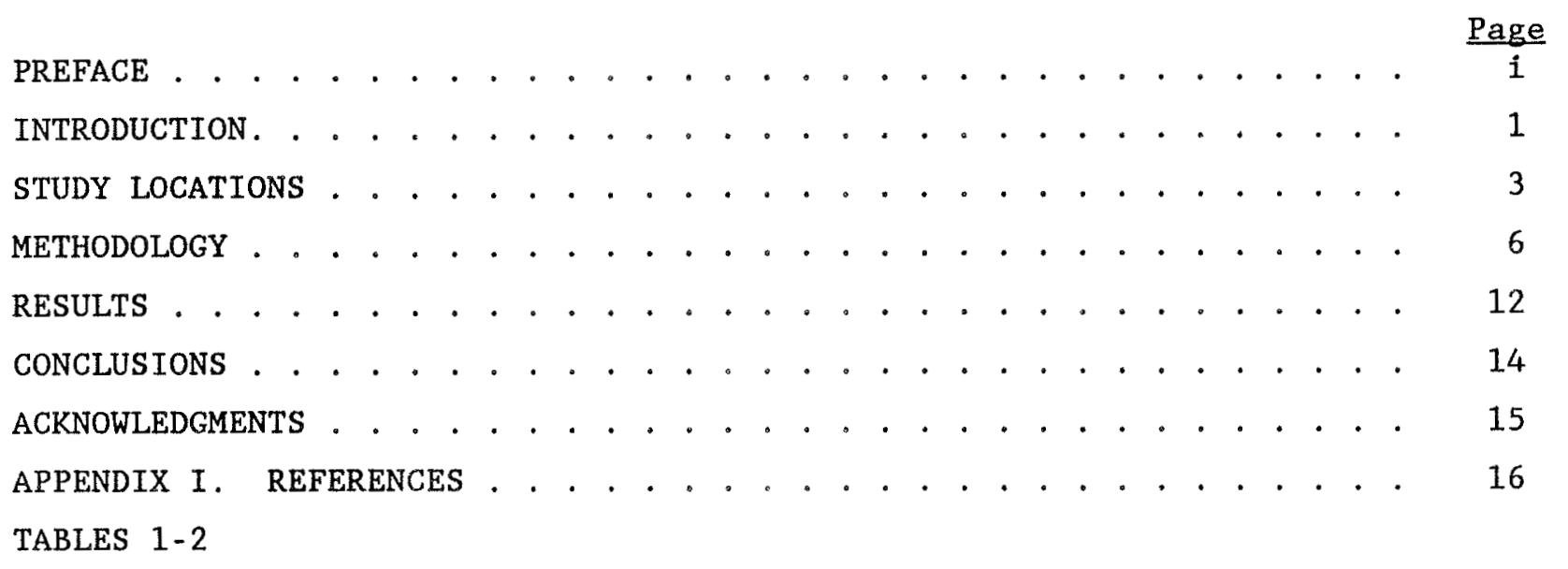

FIGURES 1-18 


\section{Wave Reflection from Natural Beaches}

Todd L. Walton Jr. ${ }^{1}$

\section{INTRODUCTION}

Wave reflection from beaches is a subject of major importance to understanding the nearshore zone and to improving coastal structure design. The level of energy flux dissipation that occurs on a beach is dependent on the magnitude of the wave reflection from the beach. Thus, in an indirect manner, wave reflection influences many coastal processes such as runup which, in turn, determines coastal design criteria such as the height of a seawall or flood protection dune.

Much information on reflection comes from limited laboratory and theoretical studies based on monochromatic water wave theory. Miche(1951) proposed a semi empirical criterion for prediction of wave reflection from sloped structures for the case of monochromatic incident waves in which limited energy dissipation occurred. Miches' (1951) results have been shown to be a reasonable "rough" approximation for monochromatic waves incident on some structure slopes (Ursell, Dean, and Yu(1960), Battjes(1974), Guza and Bowen(1976)). Moraes(1970) performed extensive small scale laboratory tests on monochromatic wave reflection from both smooth and rough slopes with the mildest slope being 1 on 10. Battjes(1974) later used the Moraes(1970) data set to derive a semiempirical expression for reflection coefficient based on Miches'(1951) work with added independent assumptions. Seelig

\footnotetext{
${ }^{1}$ Hydraulic Engineer, U.S. Army Corps of Engineers, Coastal Engineering Research Center, U.S.A.E. Waterways Experiment Station, Vicksburg, MS.
} 
and Ahrens(1981) further refined the Battjes(1974) reflection coefficient expression by empirical curve fitting.

Reflection from natural (mild, rough, non-linear in profile) beaches under irregular wave action is considerably more complex and little is presently known concerning such processes. To date, measurements of wave reflection coefficients from beaches have been made primarily via measurements in the nearshore zone, typically using either a best fit of the standing wave amplitude pattern to produce a composite reflection coefficient (Suhayda(1974)), or using linear long wave theory to calculate the composite reflection coefficient (Takezawa et al.(1988)) or to calculate the frequency dependent reflection coefficient (Tatavarti et al.(1988)). Debate in the literature has existed as to whether the observed phenomenon is truly reflection (i.e. standing waves) or cross shore spatial amplitude variability due to edge wave effects (Guza(1974)).

An important question that remains to be answered is whether the reflected wave energy from a beach is an important component of energy flux from an engineering point of view. For example, if nonlinear interaction within the surf zone cascades energy down the spectra toward lower frequencies as suggested by a red shift of energy in the nearshore spectra seen in many studies (Guza and Thornton(1989), Elgar and Guza(1985), and Freilich and Guza(1984)), the question arises as to whether a significant amount of this energy escapes from the surf zone in an offshore direction. If significant amounts of energy are found to be escaping from the surf zone in an offshore direction then actual energy available for surf zone processes such as set up and runup might be considerably less than what is typically assumed in engineering calculations as the incident wave energy. The present paper reports on 
an attempt to address this issue via separation of the measured wave field at an offshore pressure-velocity sensor gage into incident and reflected wave energy at two field sites.

\section{STUDY LOCATIONS}

The two sites at which offshore wave information and beach profile information were collected are shown in Figure 1. The first site to be addressed is Duck, N.C. on the Outer Banks of the North Carolina coastline. The Duck site is in the middle of an approximately $100 \mathrm{~km}$ uninterrupted stretch of barrier island exposed to the Atlantic Ocean. Duck was the site of a major nearshore hydrodynamics and sediment transport field experiment in October 1986 (Birkemeier et al.(1989)). The primary extent of the experiment was within the property limits of an Army Corps of Engineers Field Research Facility at Duck. The beach at this site has a steep foreshore with an average slope of 1:10 while the offshore contains a bar feature with varying amplitude and position on the nearshore profile depending on the wave climate. The grain size characteristics of the beach typically exibit bimodality with sands predominantly ranging from 0.15 to $0.30 \mathrm{~mm}$ in size and coarse shell fractions ranging predominantly from 0.5 to $3 \mathrm{~mm}$ in size. Numerous oceanographic instruments were deployed offshore in an attempt to obtain a quality data set for better understanding of nearshore processes and hydrodynamics. In particular, the present analysis is based on data from a pressure sensor and bidirectional orthogonal axis electromagnetic current meter that was contained on a tripod located on the sea bed in approximately 6.5 meters of water depth about 500 meters south of a research 
pier and approximately 500 meters offshore. The pressure sensor was located on the tripod approximately 1.45 meters above the sea bed while the current meter sensor ball was located on the tripod 1.71 meters above the sea bed. One channel of the bidirectional current meter was directed in the onshore- offshore direction while the other channel of the current meter was orthogonal to the first channel and oriented in the longshore direction. The instrument collected continuous data (pressure $=p$, velocity $=u, v$ ) at sampling increments of 0.5 seconds for 238 minutes, four times per day for a two week period during October 1986. The puv records were further broken down into 34 minute records for time series processing, although two continuous records of 136 minutes in length were also investigated. Further details on the puv instrument, the data collection, the instrument location, and beach characteristics at the site are given in Birkemeier et al.(1989). The primary records analyzed for the present study consist of data from a storm event with offshore significant wave heights exceeding 3 meters that occurred during the period October 10-14, 1986. Wave height, period, and direction during the time period of interest are given in Table 1 adopted from Birkemeier et al.(1989). The method of wave direction analysis for this gage is discussed in Grosskopf(1981). The azimuth angle of the offshore perpendicular to the beach is approximately 70 degrees true north, the same angle as the wave direction approach during the latter portion of the storm, thus, the predominant wave direction was approximately perpendicular to the beach during the period of interest. The predominance of waves in a cross shore direction is confirmed by the comparison of cross shore velocity variance to the variance of the alongshore velocity component at the gage site. In all cases analyzed, the ratio of alongshore velocity variance to cross shore velocity variance was less than 15 percent and mean 
alongshore current was less than $0.1 \mathrm{~m} / \mathrm{sec}$.

The second site to be addressed is Ocean City, Md. where the first phase of a major beach nourishment project was completed in October 1988. Beach characteristics of the pre and post fill project are discussed in Hansen(1989). During the study period the beach directly landward of the offshore sensor site had a relatively steep nearshore slope of approximately 1:15 out to about 5 meters of water depth and a mild offshore slope approximately 1:150 in the deeper water offshore. The grain size characteristics of the beach show predominantly quartz sands ranging from 0.15-0.3 in grain size (see Hansen(1989)). During the pre and post nourishment phases of this beach nourishment project a bottom resting tripod containing a pressure sensor and a bidirectional orthogonal axis electromagnetic current meter was collecting wave and current data at sampling intervals of 1 second with continuous data records of 17 minutes every 1 to 4 hours. The tripod location was approximately 900 meters offshore of the mid portion of Ocean City beach (83rd Street) in approximately 10.8 meters of water. The pressure sensor on the tripod was 0.20 meters above the sea bed while the current sensor ball on the tripod was 0.46 meters above the sea bed. One channel of the bidirectional current meter was directed in the onshore-offshore direction while the other channel of the current meter was orthogonal to the first channel and oriented in the longshore direction. During the period of 21-23 May 1990 , a strong weather system moved in over the area of concern creating significant wave heights greater than 1.6 meters offshore of the beach. The data to be discussed in the following sections is from this period in time. Wave height, period, and direction during this study period is shown in Table 2. The azimuth angle of the offshore perpendicular to the beach is approximately 90 degrees true north. The method 
of wave direction analysis for this site is discussed in Grosskopf(1981). The predominant wave direction for the records subsequently analyzed was approximately perpendicular to the beach. The predominance of waves in a cross shore direction was confirmed by comparison of the alongshore velocity variance to the cross shore velocity variance. In all cases analyzed, the ratio of the alongshore velocity variance to the cross shore variance was less than 30 percent and mean alongshore directed velocity at the gage site was less than $0.2 \mathrm{~m} / \mathrm{sec}$.

\section{METHODOLOGY}

In the present case, long crested waves are assumed traveling in an onshore direction (i.e. toward the beach) as shown in Fig. 2. The surface elevation for strictly onshore directed waves can be described as a summation of waves of various incident amplitudes and phases where one such frequency wave component is defined at location $x$ to be of the form:

$$
\eta^{i n}(n \triangle t)=a_{m}^{i n} \cos \left(\overrightarrow{k_{m}} \cdot \vec{x}-\sigma_{m} n \triangle t\right)
$$

where $\sigma_{m}=2 \pi f_{m}=$ radial frequency, $f_{m}=$ wave frequency for given frequency com-

ponent $m, \overrightarrow{k_{m}}=$ wave number, and $a_{m}^{i n}=$ incident wave amplitude. The superscript "in" refers to the wave approaching toward the beach (see Fig. 2). The incoming phase at $x=0, t=0$ has been assumed equal to zero without loss of generality.

At the beach a portion of the wave energy is "reflected" resulting in an outgoing wave train surface elevation defined for one frequency component as:

$$
\eta^{\text {out }}(n \Delta t)=a_{m}^{\text {out }} \cos \left(\overrightarrow{k_{m}} \cdot \vec{x}+\sigma_{m} n \Delta t+\xi_{m}\right)
$$

where a phase change $\xi_{m}$ between incident and "reflected" waves has been assumed 
for generality. In the present situation the term "reflected" is used in a general manner to specify the existence of a partially standing wave field offshore. The outgoing wave component at a given frequency may be either a direct reflection of the incoming wave train from the beach at the input frequency, or, a free wave created within the surf zone via non-linear interaction of incident waves and then reflected from the beach or directly generated in an outgoing direction by surf zone forcing in some manner (see for example Symonds et al.(1982)). The "reflection" coefficient can be defined for this one component (one frequency) wave system as:

$$
r_{m}=\frac{a_{m}^{o u t}}{a_{m}^{i n}}
$$

The water surface elevation for a composite sum of waves at harmonic frequencies can be defined in terms of a finite Fourier series as:

$$
\eta_{n}=\eta(n \Delta t)=\sum_{m=0}^{N-1}\left(a_{m}^{i n n} \cos \left(\overrightarrow{k_{m}} \cdot \vec{x}-\sigma_{m} n \Delta t\right)+a_{m}^{\text {out }} \cos \left(\overrightarrow{k_{m}} \cdot \vec{x}+\sigma_{m} n \Delta t+\xi_{m}\right)\right)
$$

where a term for the mean water surface ( $m=0$ component) has been included. Utilizing the notation for a lag domain discrete Fourier transform series (DFT) as per Borgman(1973):

$$
x_{n}=x(n \Delta t)=\sum_{m=0}^{N-1} X_{m} \exp \left(\frac{i 2 \pi m n}{N}\right) \Delta f
$$

with

$$
X_{m}=X(m \triangle f)
$$

and the frequency domain discrete Fourier transform series (DFT) as:

$$
X_{m}=\sum_{n=0}^{N-1} x_{n} \exp \left(\frac{-i 2 \pi m n}{N}\right) \Delta t
$$


the water level surface elevation for the composite incident and reflected wave train series can be written as:

$$
\eta_{n}=\eta(n \Delta t)=\sum_{m=0}^{N-1}\left(A_{m}^{i n} \exp \left(\frac{i 2 \pi m n}{N}\right)+A_{m}^{\text {out }} \exp \left(\frac{i 2 \pi m n}{N}\right)\right) \Delta f
$$

where $A_{m}^{i n}$ and $A_{m}^{\text {out }}$ are the complex amplitudes of the incident and reflected waves at frequency component $m$.

The bottom pressure as recorded by a subsurface pressure sensor for one wave frequency component (incident and reflected) is given by (Dean and Dalrymple (1984)) as:

$$
p(n \triangle t)=\rho g K_{p_{m}} \eta(n \Delta t)
$$

with

$$
K_{p_{m}}=\frac{\cosh \left(\left|\overrightarrow{k_{m}}\right| s_{p}\right)}{\cosh \left(\left|\overrightarrow{k_{m}}\right| h\right)}
$$

where $\rho=$ density of seawater, $g=$ acceleration of gravity, $h=$ water depth, $s_{p}=$ height of pressure sensor above the sea bed, and $K_{p_{m}}$ is often referred to as the dynamic pressure response factor for a given frequency component $m$.

For a wave train made up of a number of wave frequency harmonic components, the pressure time series can also be written in a similar manner to that of surface elevation as follows:

$$
p_{n}=p(n \Delta t)=\sum_{m=0}^{N-1} \rho g K_{p_{m}}\left(A_{m}^{i n} \exp \left(\frac{i 2 \pi m n}{N}\right)+A_{m}^{o u t} \exp \left(\frac{i 2 \pi m n}{N}\right)\right) \Delta f
$$

The water wave particle velocity in the onshore-offshore direction as recorded by a subsurface current meter for one wave frequency component is given by (Dean and 
Dalrymple (1984)):

$u(n \triangle t)=\sigma_{m} K_{v_{m}} \cos \theta_{m}\left(a_{m}^{i n} \cos \left(\overrightarrow{k_{m}} \cdot \vec{x}-\sigma_{m} n \Delta t\right)-a_{m}^{o u t} \cos \left(\overrightarrow{k_{m}} \cdot \vec{x}+\sigma_{m} n \Delta t+\xi_{m}\right)\right)$

with $\theta_{m}$ being the wave direction for a given frequency component as defined in Fig. 2 , and where:

$$
K_{v_{m}}=\frac{\cosh \left(\left|\overrightarrow{k_{m}}\right| s_{v}\right)}{\sinh \left(\left|\overrightarrow{k_{m}}\right| h\right)}
$$

with $s_{v}=$ height of velocity sensor above the sea bed.

For a wave train made up of a number of wave frequency components the onshoreoffshore velocity time series can also be written in a similar manner to that of surface elevation as follows:

$$
u_{n}=u(n \Delta t)=\sum_{m=0}^{N-1} \sigma_{m} K_{v_{m}} \cos \theta_{m}\left(A_{m}^{i n} \exp \left(\frac{i 2 \pi m n}{N}\right)-A_{m}^{\text {out }} \exp \left(\frac{i 2 \pi m n}{N}\right)\right) \Delta f
$$

In a similar manner the lag domain discrete Fourier transform series of the measured pressure and velocity values can be defined as:

$$
p_{n}=p(n \Delta t)=\sum_{m=0}^{N-1} P_{m} \exp \left(\frac{i 2 \pi m n}{N}\right) \Delta f
$$

and

$$
u_{n}=u(n \Delta t)=\sum_{m=0}^{N-1} U_{m} \exp \left(\frac{i 2 \pi m n}{N}\right) \Delta f
$$

Equating frequency component terms of the lag domain DFT series, the following equations for the complex amplitude pressure and velocity terms can be found as:

$$
P_{m}=\rho g K_{p_{m}}\left(A_{m}^{\text {in }}+A_{m}^{o u t}\right)
$$

and

$$
U_{m}=\sigma_{m} K_{v_{m}} \cos \theta_{m}\left(A_{m}^{i n}-A_{m}^{o u t}\right)
$$


Using the above two equations, the complex wave amplitudes $A_{m}^{i n}$ of the incoming wave train and $A_{m}^{o u t}$ of the outgoing wave train can be found as:

$$
A_{m}^{i n}=\frac{P_{m}}{2 \rho g K_{p_{m}}}+\frac{U_{m}}{2 \sigma_{m} K_{v_{m}} \cos \theta_{m}}
$$

and

$$
A_{m}^{o u t}=\frac{P_{m}}{2 \rho g K_{p_{m}}}-\frac{U_{m}}{2 \sigma_{m} K_{v_{m}} \cos \theta_{m}}
$$

In the above equations the sensitivity of the incoming and outgoing wave train complex amplitude modulus to the direction of the incoming and outgoing wave train is seen to be relatively small by virtue of the $\cos \theta_{m}$ term in the denominator of the velocity frequency domain term. It is also noted that if the wave velocity component is assumed to be in the onshore-offshore direction, the complex inbound amplitude is mimimized while the outgoing wave train complex amplitude coefficient is maximized, thus maximizing computed reflection.

In the present context, the spectral energy content of a signal can be defined as the modulus squared divided by the record length (Borgman(1973)), hence the incident and "reflected" spectral energy for a given frequency component $f=m \Delta f=\frac{m}{N \Delta t}$ are given as:

$$
S_{m}^{i n}=\frac{\left|A_{m}^{i n}\right|^{2}}{N \triangle t}
$$

and

$$
S_{m}^{\text {out }}=\frac{\left|A_{m}^{\text {out }}\right|^{2}}{N \Delta t}
$$

The frequency dependent reflection coefficient can be defined as:

$$
r_{m}=\frac{\left|A_{m}^{\text {out }}\right|}{\left|A_{m}^{i n}\right|}
$$


the ratio of the outgoing wave train complex amplitude modulus to the incoming wave train complex amplitude modulus in the situation where incident energy is greater than "reflected" energy, or, in an ad hoc manner as the inverse of Equation 23 with a negative sign in the situation where there is more outgoing "reflected" wave energy than incoming "incident" wave energy.

As a check of the reasonableness of a linear wave theory relationship between the pressure and velocity signals, the coherency squared can be compared with a value of 1.0 suggesting a perfect linear relationship in the case of "smoothed" coherency estimates (Bendat and Piersol (1986)). The coherency squared for the pressure and velocity signals is defined as (Bendat and Piersol (1986)):

$$
\gamma_{u p_{m}}^{2}=\frac{\left|S_{u p_{m}}\right|^{2}}{S_{u u_{m}} S_{p p_{m}}}
$$

with

$$
S_{u u_{m}}=\frac{\left|U_{m}\right|^{2}}{N \triangle t}
$$

the spectra of the onshore-offshore velocity component signal, and

$$
S_{p p_{m}}=\frac{\left|P_{m}\right|^{2}}{N \Delta t}
$$

the spectra of the pressure signal, and

$$
S_{u p_{m}}=\frac{U_{m}^{*} P_{m}}{N \Delta t}
$$

the cross spectra of the velocity and pressure signals, where the quantity ()$^{*}$ represents the complex conjugate of the argument in parenthesis. 


\section{RESULTS}

A short segment of the measured thirty four minute records of pressure head (meters of water) and onshore- offshore velocity component $(\mathrm{m} / \mathrm{sec}$.) are shown in Figures 3a and 7a for the Duck, N.C. site for the record periods beginning 0028 October 11,1986 , and 0614 October 11, 1986. Coherence estimates between the pressure and velocity signals for the same time periods (thirty four minute records) as computed via Equation 24 with smoothed spectral estimators are shown in Figures $3 \mathrm{~b}$ and $7 \mathrm{~b}$. As expected, there is a high degree of coherence for the two signals. Smoothed spectral energy of measured pressure head $S_{p p}$ and onshore-offshore velocity component $S_{u u}$ for the two time periods are shown in Figures 4 and 8 . Smoothed spectral energy content of incident wave train water surface elevation $S^{\text {in }}$ and of "reflected" wave train water surface elevation $S^{\text {out }}$ as computed via Equations 21 and 22 are shown in Figures 5 and 9. Reflection coefficient computed from the smoothed ingoing and outgoing wave train is shown as a function of frequency in Figures 6 and 10.

The frequency plots have been smoothed by dividing record lengths into 8 subrecords, removing the mean of the subrecords, calculating spectra of the subrecords, and then averaging energy content within frequency bins therefore providing an equivalent of 16 degree of freedom smoothed spectral estimators (Bendat and Piersol(1989)). In the computation of the incident and reflected wave trains a high frequency cutoff of 0.25 hertz was utilized to prevent amplification of noise due to the hydrodynamic damping factors in the denominators of Equations 19 and 20. Plots of both $S^{\text {in }}$ and $S^{\text {out }}$, the spectral energy estimates of the incident and reflected wave train elevations, show dashed curves above and below the average frequency 
content of the signals representing one root mean square error from the average as defined by Bendat and Piersol(1989), Chapt. 9, pg. 295. Maximum reflection over frequency bands with significant energy content where coherence is high show reflection to be less than ten percent suggesting that reflected energy from the beach is less than one percent of the incident energy. Note that reflection plots are scaled on the vertical scale from 1 to -1 . This scaling was used to allow for the possibility of "reflected" energy greater than "incident" energy as perhaps via nonlinear energy transfer within the surf zone of beaches and generation of outgoing energy via some mechanism as discussed in the previous section. In the case of "outgoing" energy greater than "incoming" energy, the inverse of Equation 23 is utilized to calculate the reflection coefficient and an ad hoc "negative" reflection coefficient terminology is adopted. This ad hoc "negative" reflection coefficient terminology allows for the possibility of energy shifts to lower frequency within the surf zone and movement of this energy back offshore. If such terminology were not adopted, the previous scenerio would lead to possible "infinite" reflection coefficient (i.e. finite outgoing long wave energy in numerator with zero incident energy in denominator) via the standard reflection coefficient definition of Equation 3.

Records from the Duck site were analyzed at 3 hour intervals over a three day period during the storm at Duck with similar results, i.e. no apparent reflected energy of important magnitude. For the two time periods shown, a record length of 136 minutes was also analyzed and results were found to be very similar to that shown for the shorter 34 minute records. There was an absence of any long wave energy of significance in either the incident or reflected wave trains, at least at periods shorter than the longest record length analyzed ( $=136$ minutes $/ 8=17$ minutes). It should 
be noted that the present analysis does not preclude the possible existence of either standing edge or progressive edge waves but does suggest for this data set that the beach provides a near total energy dissipator from a two dimensional standpoint. The results of the analysis confirm the time plots of Fig. 3a and 6a which lack any suggestion of reflected wave energy in the time series.

Plots similar to the above Duck site plots for the Ocean City site are shown in Figs. 11 thru 18 for the two record periods beginning 0400 May 22, 1990, and 1600 May 22,1990 . In the Ocean City case the records were 17 minutes long and frequency plots were smoothed by dividing record lengths into 4 subintervals, removing the means of the subintervals, calculating spectra of the subintervals, and averaging energy content within frequency bins, providing an equivalent of 8 degree of freedom smoothed spectral estimators. A high frequency cutoff of 0.25 hertz was also utilized for the Ocean City data for the reasons discussed in the preceeding analysis of the Duck data. Again, dashed curves in the incident wave train spectra $S^{i n}$ and reflected wave train spectra $S^{\text {out }}$ plots provide a plus or minus one root mean square error from the averaged spectral energy.

Upon analysis the Ocean City spectral plots of incident and reflected wave train elevation spectral energy also show a lack of significant "reflected" wave energy and consequent low reflection coefficient in the energy bands of significance. Records from the Ocean City site were analyzed at 3 hour intervals during the period 21 May thru 23 May 1990 and were found to be similar to the plots shown above (i.e. no significant wave reflection).

CONCLUSIONS 
The present study has been a first attempt to look at the importance of wave "reflection" from beaches. Additionally the method of analysis utilized in the present study allows for the possibility of "outgoing/reflected" energy to be larger than the "incoming/incident" energy. In the two data sets discussed, "reflection" did not appear to be a significant engineering consideration in a two dimensional perspective. Trapped energy phenomenia such as edge waves were not investigated in the present analysis.

Although definitive conclusions cannot be made from such limited analysis of the data, it appears that a reasonable first approximation to engineering coastal phenomenia can consider natural beaches to be effective energy dissipators, at least in the cross shore direction.

\section{ACKNOWLEDGMENTS}

The work presented herein was conducted under the Irregular Wave Runup work unit of the Shore Protection and Beach Restoration Program, U.S. Army Corps of Engineers, Coastal Engineering Research Center, Waterways Experiment Station, Vicksburg, Mississippi. The author acknowledges and is grateful for use of data collected by the Field Research Facility (CERC) group at the Duck, N.C. site and by the Prototype Measurement and Analysis (CERC) group in Vicksburg, MS. Permission was granted by the Office of the Chief of Engineers, U. S. Army Corps of Engineers to publish this information. 


\section{APPENDIX I. REFERENCES}

Battjes,J.A.(1974). Computation of Set-up, Longshore Currents, Runup and Overtopping Due to Wind Generated Waves, Dissertation, Technische Hogeschool, Delft, Netherlands.

Bendat, J.S., and Pierson, A.G.(1986). Random Data: Analysis and Measurement Procedures, Second Ed., John Wiley and Sons Publishers, New York, N.Y.

Birkemeier, W.A.; Baron, C.F.; Leffler,M.W.; Hathaway, K.K.; Miller, H.C.; Strider, J.B. Jr.(1989). Superduck Nearshore Processes Experiment Data Summary: CERC Field Research Facility, Miscellaneous Paper CERC-89-16, U.S. Army Corps of Engineers, Waterways Experiment Station, Coastal Engineering Research Center, Vicksburg, MS.

Borgman, L.E.(1973). Spectrum Analysis of Random Data, Report No. 23, Statistics Dept., Univ. of Wyoming, Laramie, WY.

Dean, R.G., and Dalrymple, R.A.(1984). Water Wave Mechanics for Engineers and Scientists, Prentice Hall Publishers, Englewood Cliffs, N.J.

Elgar,S. and Guza,R.T.(1985). Observations of Bispectra of Shoaling Surface Gravity Waves, J. Iluid Mechanics, Vol.161, pp 425-448.

Freilich, M.H., and Guza, R.T.(1984). Nonlinear Effects on Shoaling Surface Gravity Waves, Phil. Trans. R. Society London, A311, 1-41.

Grosskopf, W.G.(1981). Computer Algorithm to Calculate a Wave Directional Spectrum and Related Parameters from a Biaxial Current Meter and Pressure 
Gage, Catagory A Computer Program and Documentation (file report), U.S. Army Corps of Engineers, Waterways Experiment Station, Coastal Engineering Research Center, Vicksburg, M.S.

Guza, R.T.(1974). Comment on Standing Waves on Beaches by J.N.Suhayda, J.Geophysical Research, Vol.79, No.36, pp.5671- 5672.

Guza, R.T., and Bowen, A.J.(1977). Resonant Interactions for Waves Breaking on a Beach, Proc. 16th Coastal Engineering Conference, ASCE, 560-579.

Hansen, M.K.(1989). Preliminary Data Report on the Hurricane Protection Project: Ocean City, Md., Miscellaneous Paper CERC-89- ,U.S. Army Corps of Engineers, Waterways Experiment Station, Coastal Engineering Research Center, Vicksburg, MS.

Miche,R.(1951). Le pouvoir reflechissant des ouvrages maritimes exposes a l'action de la houle, Ann. des Ponts et Chaussees, 121e Annee,pp. 285-319.

Moraes, C.C.(1970). Experiments of Wave Reflexion on Impermeable Slopes, Proc. 12th Conference Coastal Engineering, ASCE, 509-521.

Seelig, W.N, and Ahrens,J.P.(1981). Estimation of Wave Reflection and Energy Dissipation Coefficients for Beaches, Revetments, and Breakwaters, Tech. Paper No. 81-1, U.S. Army Corps of Engineers, Coastal Engineering Research Center, Ft. Belvoir, Va.

Suhayda, J.N.(1974). Standing Waves on Beaches, J.Geophysical Research, Vol.79, No. 21, pp. 3065-3071. 
Symonds, G.; Huntley, D.A.; and Bowen, A.J.(1982). Two- Dimensional Surf Beat: Long Wave Generation by a Time-Varying Breakpoint, Jour. Geophysical Research, Vol 87, pp. 492-498.

Takezawa, M.; Mizuguchi, M.; Hotta,S.; and Kubota, S.(1988). Wave Runup on a Natural Beach, Vol.1, Proc. 21st Coastal Engineering Conference, ASCE, pp.151-165. Tatavarti, R.V.S.N.; Huntley, D.A.; and Bowen, A.J.(1988). Incoming and Outgoing Wave Interactions on Beaches. Proc. 21st Coastal Engineering Conference, ASCE, pp. 136-150.

Thornton, E.B. and Guza, R.T.(1989). Wind Wave Transformation, Chapt. 8, Nearshore Sediment Transport, Ed. R.J.Seymour, Plenum Press, New York, N.Y.

Ursell, R., Dean, R.G., and Yu, Y.S.(1960). Forced Small- Amplitude Water Waves: A Comparison of Theory and Experiment, Jour. of Fluid Mechanies, Vol. 7, Pt.1, Jan. 1960, pp. 33-52. 
Table 1: Wave Climatology - Duck, N.C.

\begin{tabular}{|c|c|c|c|}
\hline Date/Time & $\begin{array}{c}U_{\text {mo }} \\
\text { meters] }\end{array}$ & $\left.\begin{array}{c}\mathrm{T}_{p} \\
{[\mathrm{sec} .]}\end{array}\right]$ & $\begin{array}{c}\text { Wave Direction } \\
\text { [degrees] }\end{array}$ \\
\hline Oct.10,1986 12,6 & 2.5 & 7.5 & 50 \\
\hline Oct.10,1986 1320 & 2.6 & 7.3 & 51 \\
\hline Oct.10,1986 $135 \%$ & 2.6 & 7.1 & 51 \\
\hline Oct.10,1986 1700 & 2.8 & 7.3 & 54 \\
\hline Oct.10,1986 1734 & 2.9 & 8.0 & 53 \\
\hline Oct.10,1986 1808 & 3.0 & 7.1 & 52 \\
\hline Oct.10,1986 1842 & 3.1 & 7.8 & 56 \\
\hline Oct.10,1986 1916 & 3.0 & 7.8 & 53 \\
\hline Oct.10,1986 1950 & 3.1 & 8.3 & 58 \\
\hline Oct.10,19862021 & 3.1 & 7.5 & 60 \\
\hline Oct.10,1986 2320 & 3.3 & 8.0 & 58 \\
\hline Oct.10,1986 2354 & 3.2 & 9.1 & 64 \\
\hline Oct.11,19860028 & 3.3 & 8.3 & 61 \\
\hline OCE.11,19860102 & 3.4 & 7.8 & 62 \\
\hline Oct.11,19860136 & 3.1 & 8.5 & 63 \\
\hline Oct.11,19860210 & 3.2 & 7.8 & 63 \\
\hline Oct.11,1986024t & 3.1 & 8.8 & 65 \\
\hline Oct.11,19860540 & 3.2 & 9.1 & 62 \\
\hline Oct.11,19860614 & 3.1 & 8.5 & 63 \\
\hline Oct.11,10860648 & 3.4 & 9.5 & 66 \\
\hline Oct.11,19860722 & 3.2 & 9.1 & 69 \\
\hline $004.11,19860756$ & 3.2 & 9.1 & 67 \\
\hline Oct.11,19860830 & 3.2 & 9.5 & 65 \\
\hline Oct.11,10860904 & 3.2 & 9.1 & 62 \\
\hline Oct.11,19361200 & 3.2 & 9.9 & 69 \\
\hline Oct.11,19861234 & 3.2 & 11.1 & 75 \\
\hline Oct.11,19861308 & 3.2 & 10.7 & 72 \\
\hline Oct.11,1986 1342 & 3.3 & 11.6 & 73 \\
\hline Oct.11,19861416 & 3.2 & 11.1 & 72 \\
\hline Oct.11,19861450 & 3.0 & 11.6 & 74 \\
\hline Ock.11,1986 1524 & 3.3 & 11.1 & 74 \\
\hline Oct.11,19861820 & 3.0 & 11.6 & 74 \\
\hline Oct.11,1083 1854 & 2.9 & 12.2 & 76 \\
\hline Oct.11,19861928 & 2.8 & 12.2 & 73 \\
\hline Oct.11,19862002 & 2.8 & 11.1 & 74 \\
\hline Oct.11,19832036 & 2.9 & 11.1 & 73 \\
\hline Oct. 1,19862110 & 2.9 & 12.2 & 73 \\
\hline Oct.11,1986 2144 & 2.8 & 11.1 & 73 \\
\hline Oc1.12,19860040 & 2.7 & 12.2 & 75 \\
\hline Oct.12,19860114 & 2.8 & 12.8 & 76 \\
\hline Oct.12,1986 0148 & 2.7 & 12.2 & 74 \\
\hline Oct.12,19860222 & 2.7 & 11.6 & 76 \\
\hline Oct.12,1986 0256 & 2.6 & 10.7 & 74 \\
\hline Oct.12,19860330 & 2.7 & 12.2 & 73 \\
\hline Oct.12,1986 0404 & 2.5 & 9.9 & 75 \\
\hline Oct.12,10860645 & 2.3 & 11.6 & 75 \\
\hline Oct.12,19860719 & 2.3 & 11.1 & 77 \\
\hline Oct.12,19860753 & 2.4 & 11.6 & 73 \\
\hline
\end{tabular}


Table 2: Wave Climatology - Ocean City, Md.

\begin{tabular}{|c|c|c|c|}
\hline Date/Time & $\begin{array}{c}H_{\text {mo }} \\
\text { [meters] }\end{array}$ & $\left.\begin{array}{c}T_{p} \\
{[\mathrm{sec} .}\end{array}\right]$ & $\begin{array}{c}\text { Wave Direction } \\
\text { [degrees] }\end{array}$ \\
\hline May $21,1990 \quad 1600$ & .97 & 4.3 & 66 \\
\hline May 21,1990 1700 & 1.16 & 4.5 & 69 \\
\hline May 21,1990 1800 & 1.33 & 5.2 & 73 \\
\hline May 21,1990 1900 & 1.25 & 6.6 & 84 \\
\hline May 21,1990 2000 & 1.38 & 6.0 & 79 \\
\hline May 21,1990 2100 & 1.53 & 4.5 & 69 \\
\hline May 21,1990 2200 & 1.54 & 6.0 & 68 \\
\hline May 21,1990 2300 & 1.50 & 6.0 & 65 \\
\hline May 22,19900000 & 1.52 & 5.2 & 65 \\
\hline May 22,19900100 & 1.54 & 7.3 & 72 \\
\hline May 22,19900200 & 1.61 & 6.0 & 61 \\
\hline May 22,1990 0300 & 1.34 & 5.2 & 68 \\
\hline May 22,19900400 & 1.24 & 7.3 & 81 \\
\hline May 22,1990 0500 & 1.20 & 8.3 & 86 \\
\hline May 22,1990 0600 & 1.35 & 7.8 & 81 \\
\hline May 22,19900700 & 1.37 & 8.3 & 82 \\
\hline May 22,19900800 & 1.29 & 7.8 & 85 \\
\hline May 22,1990 0900 & 1.14 & 8.8 & 81 \\
\hline May 22,19901000 & 1.16 & 8.3 & 83 \\
\hline May 22,19901100 & 1.22 & 8.3 & 81 \\
\hline May 22,19901200 & 1.13 & 8.8 & 78 \\
\hline May 22,19901300 & 1.27 & 8.8 & 65 \\
\hline May 22,19901400 & 1.09 & 8.8 & 80 \\
\hline May 22,19901500 & 1.10 & 9.5 & 98 \\
\hline May 22,19901600 & 1.21 & 9.5 & 95 \\
\hline May 22,1990 1700 & 1.18 & 4.2 & 73 \\
\hline May 22,1990 1800 & 1.22 & 7.8 & 85 \\
\hline May 22,19901900 & 1.20 & 7.8 & 83 \\
\hline May 22,19902000 & 1.13 & 8.8 & 79 \\
\hline May 22,19902100 & 1.15 & 6.9 & 87 \\
\hline May 22,19902200 & 1.21 & 5.2 & 85 \\
\hline May 22,19902300 & 1.05 & 8.8 & 84 \\
\hline May 23,19900000 & 0.97 & 8.8 & 83 \\
\hline May 23,19900100 & 1.15 & 9.5 & 75 \\
\hline May 23,1990 0200 & 0.97 & 9.5 & 91 \\
\hline May 23,19900300 & 0.78 & 9.5 & 93 \\
\hline
\end{tabular}




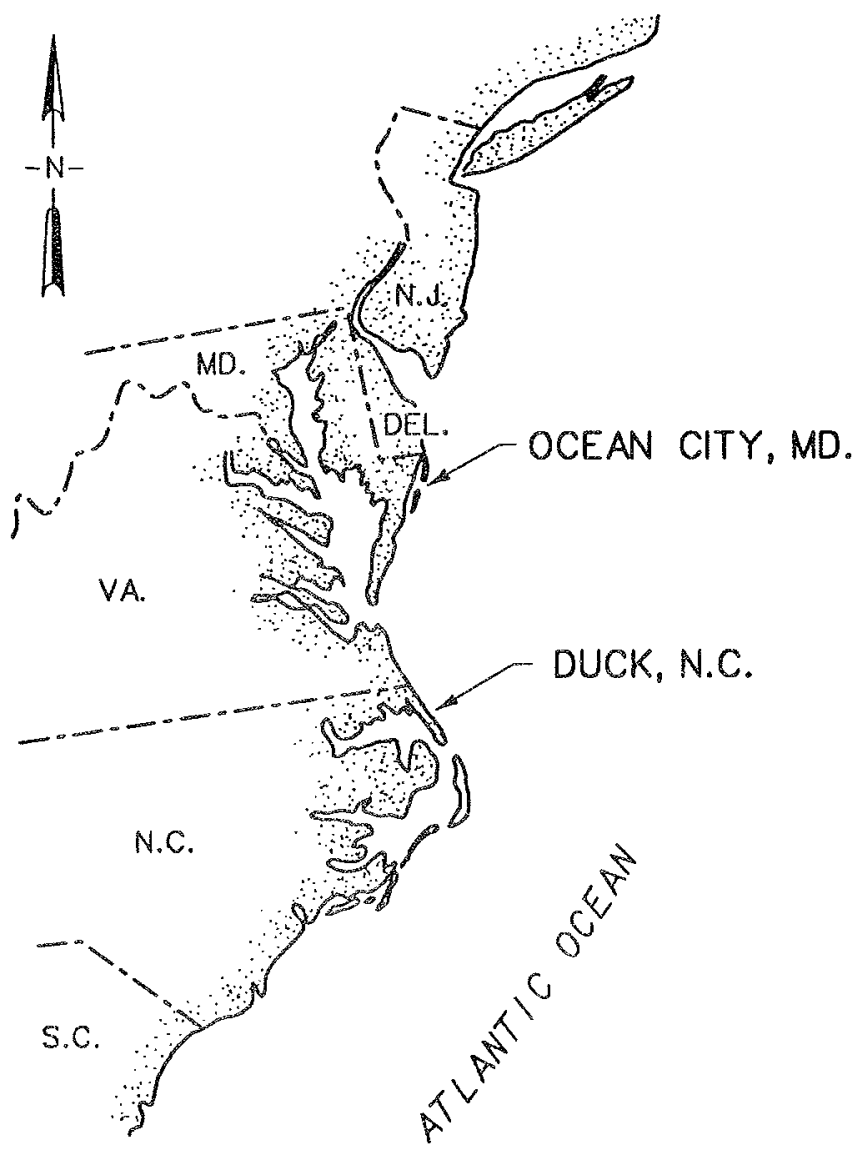

FIG. 1. SITE MAP OF STUDY LOCATIONS 


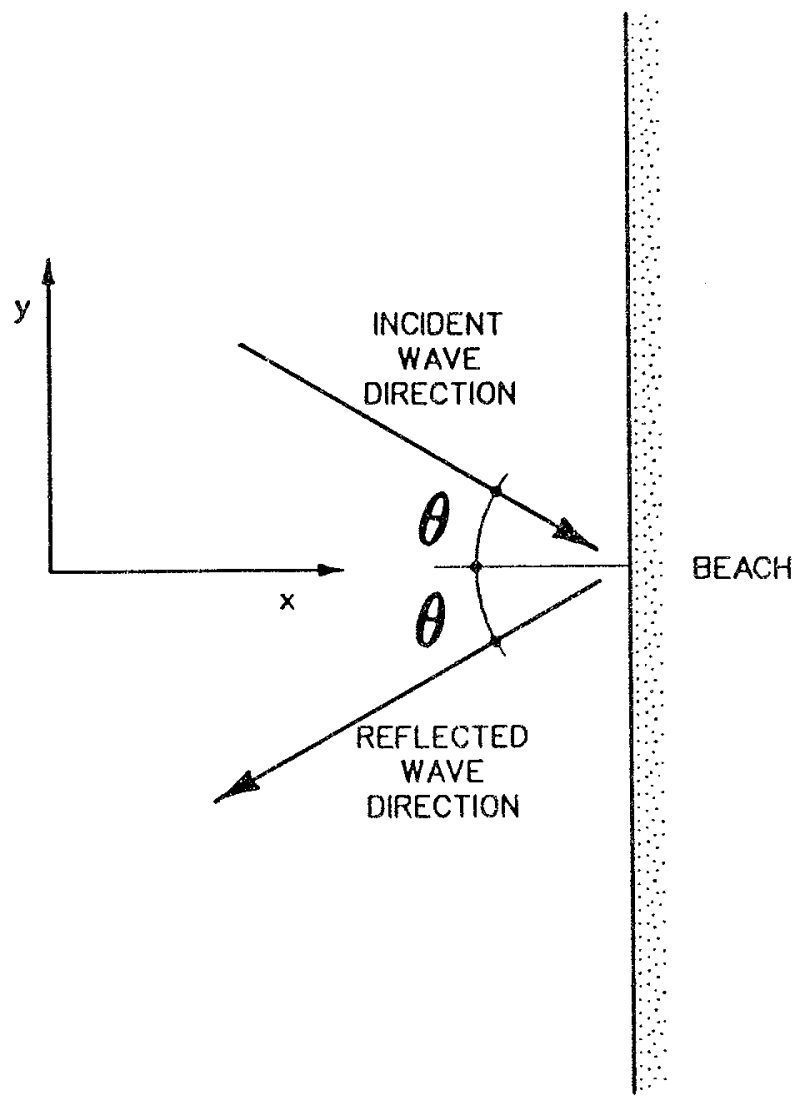

FIG. 2. COORDINATE SYSTEM 

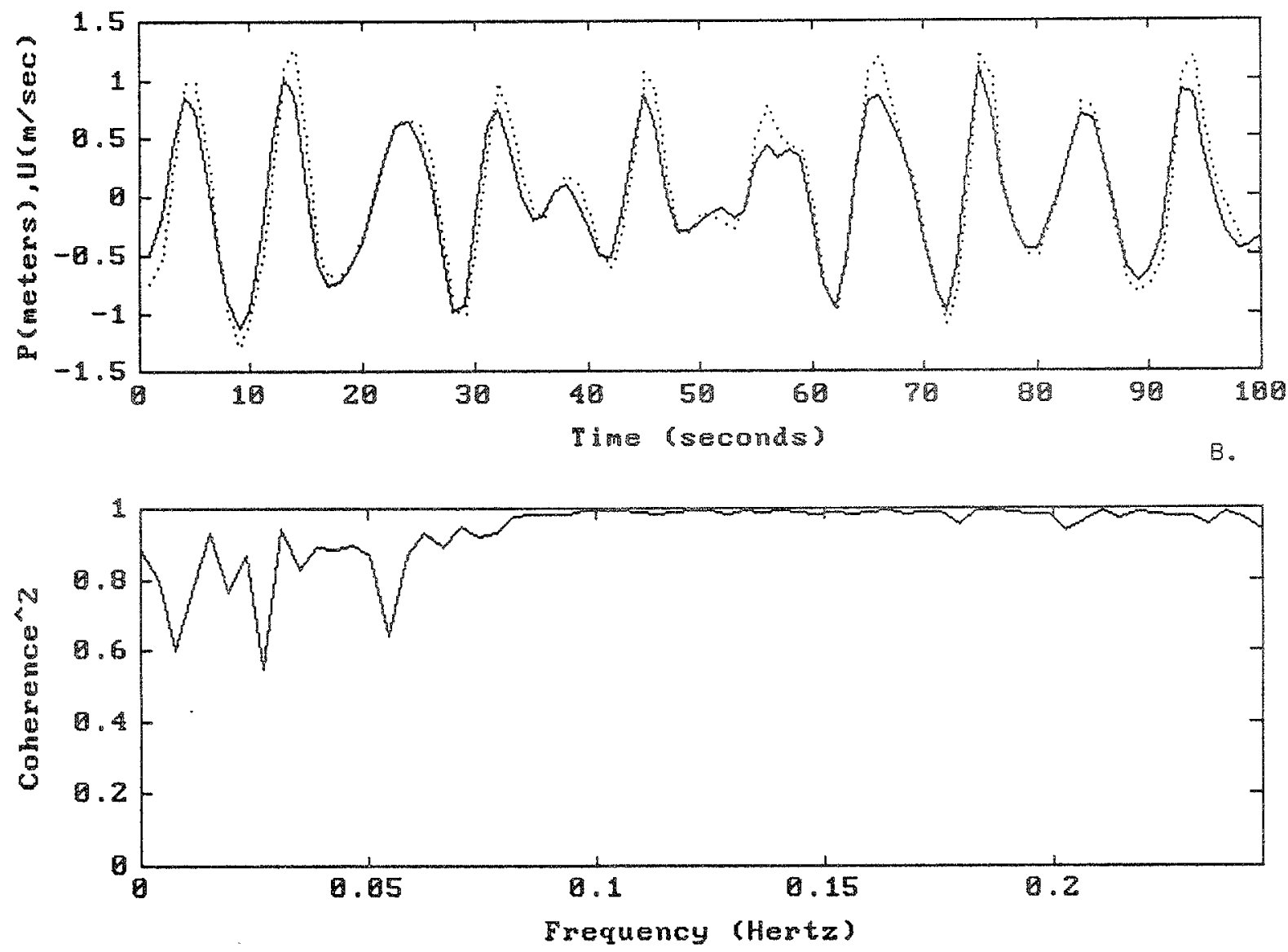

FIG. 3 (a) PRESSURE AND VELOCITY TIME RECORD

(b) COHERENCE SQUARED OF PRESSURE, ONSHORE-OFFSHORE VELOCITY 

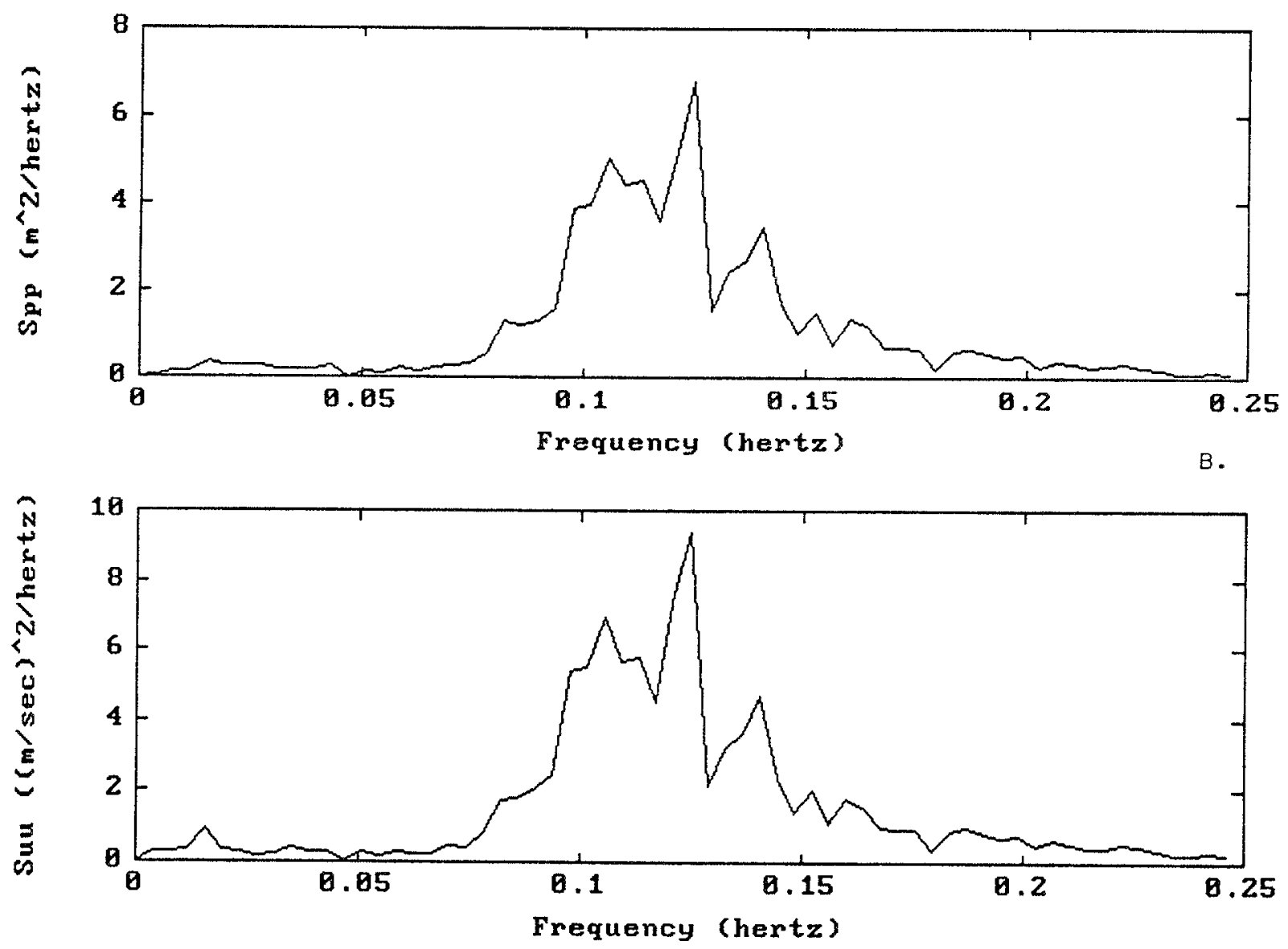

FIG. 4 (a) VARIANCE SPECTRUM OF PRESSURE

(b) VARIANCE SPECTRUM OF ONSHORE-OFFSHORE VELOCITY 

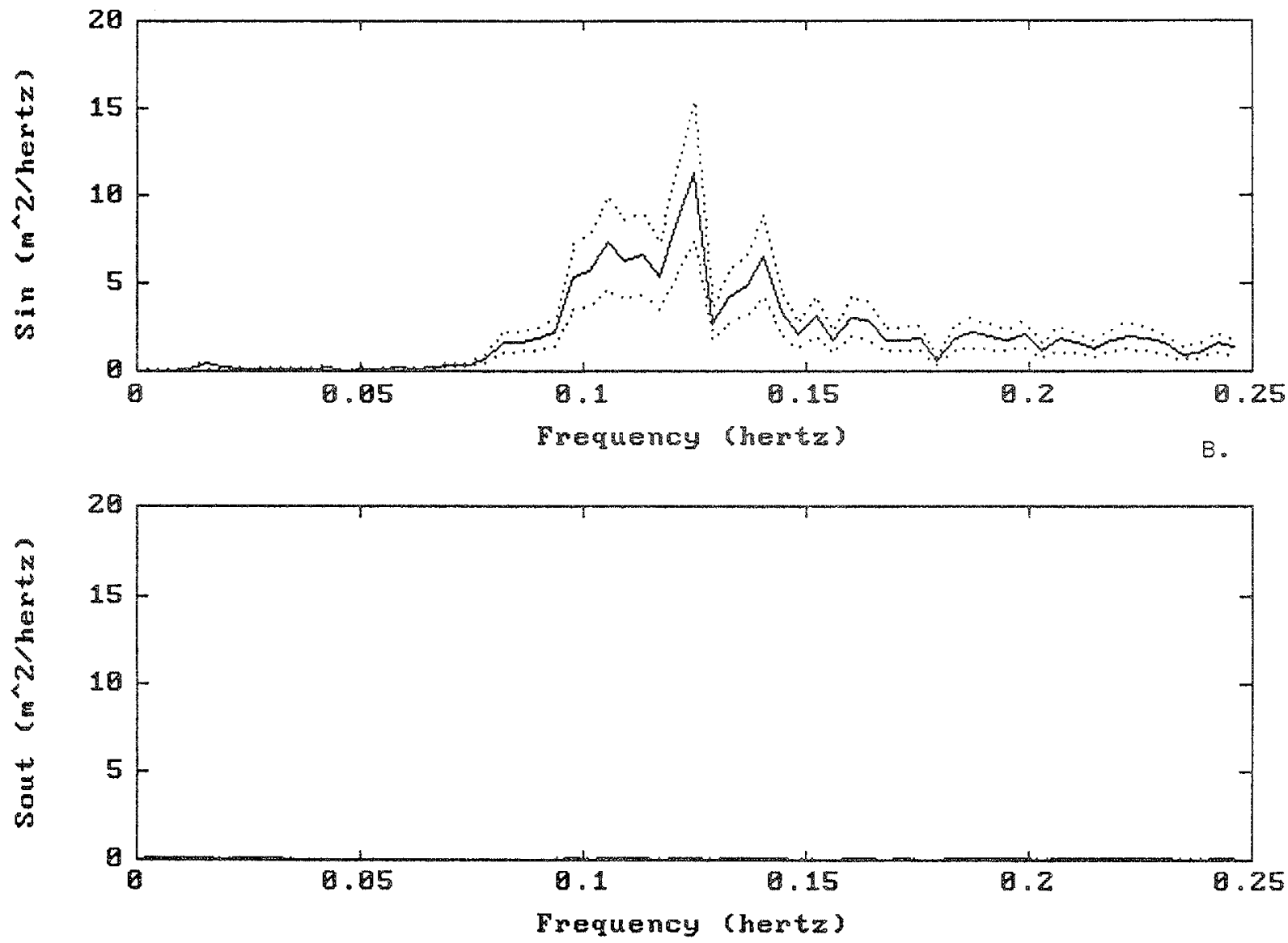

FIG. 5 (a) VARIANCE SPECTRUM OF INCIDENT WAVE TRAIN SURFACE ELEVATION (b) VARIANCE SPECTRUM OF REFLECTED WAVE TRAIN SURFACE ELEVATION 
LUCK 0614,11 OCTOBER 1986

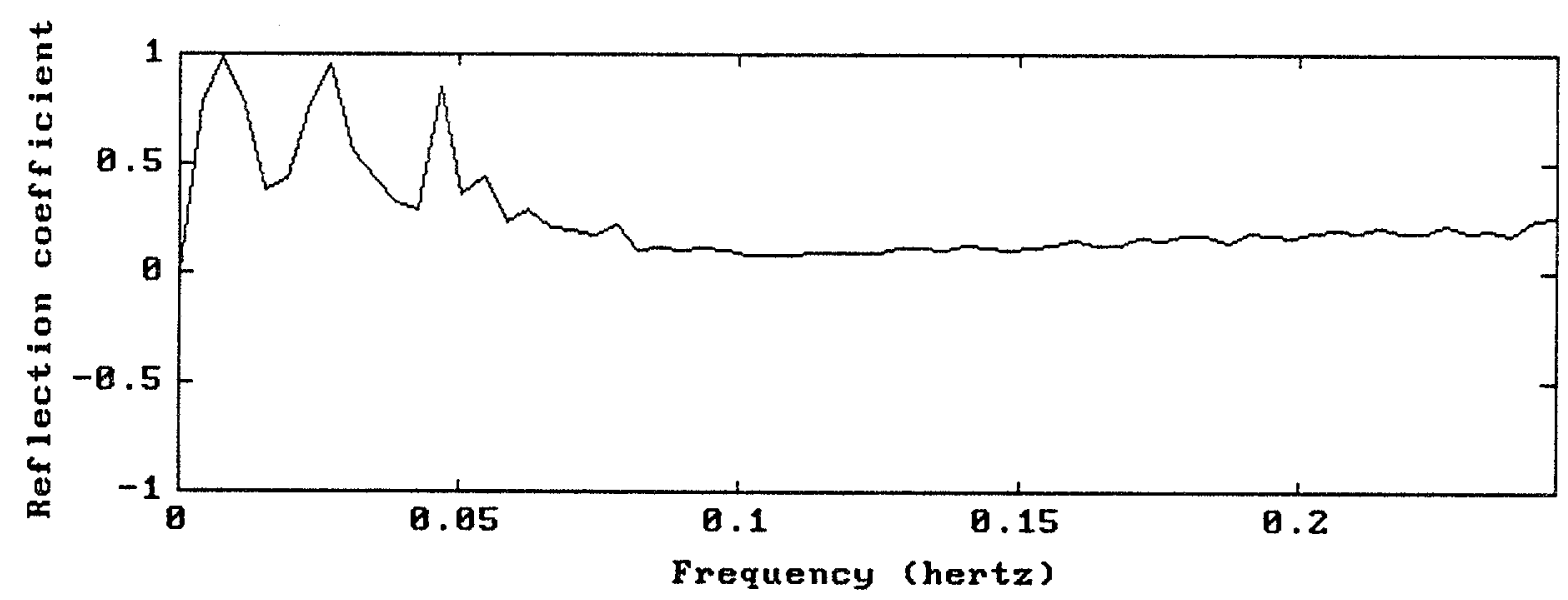

FIG. 6 REFLECTION COEFFICIENT 

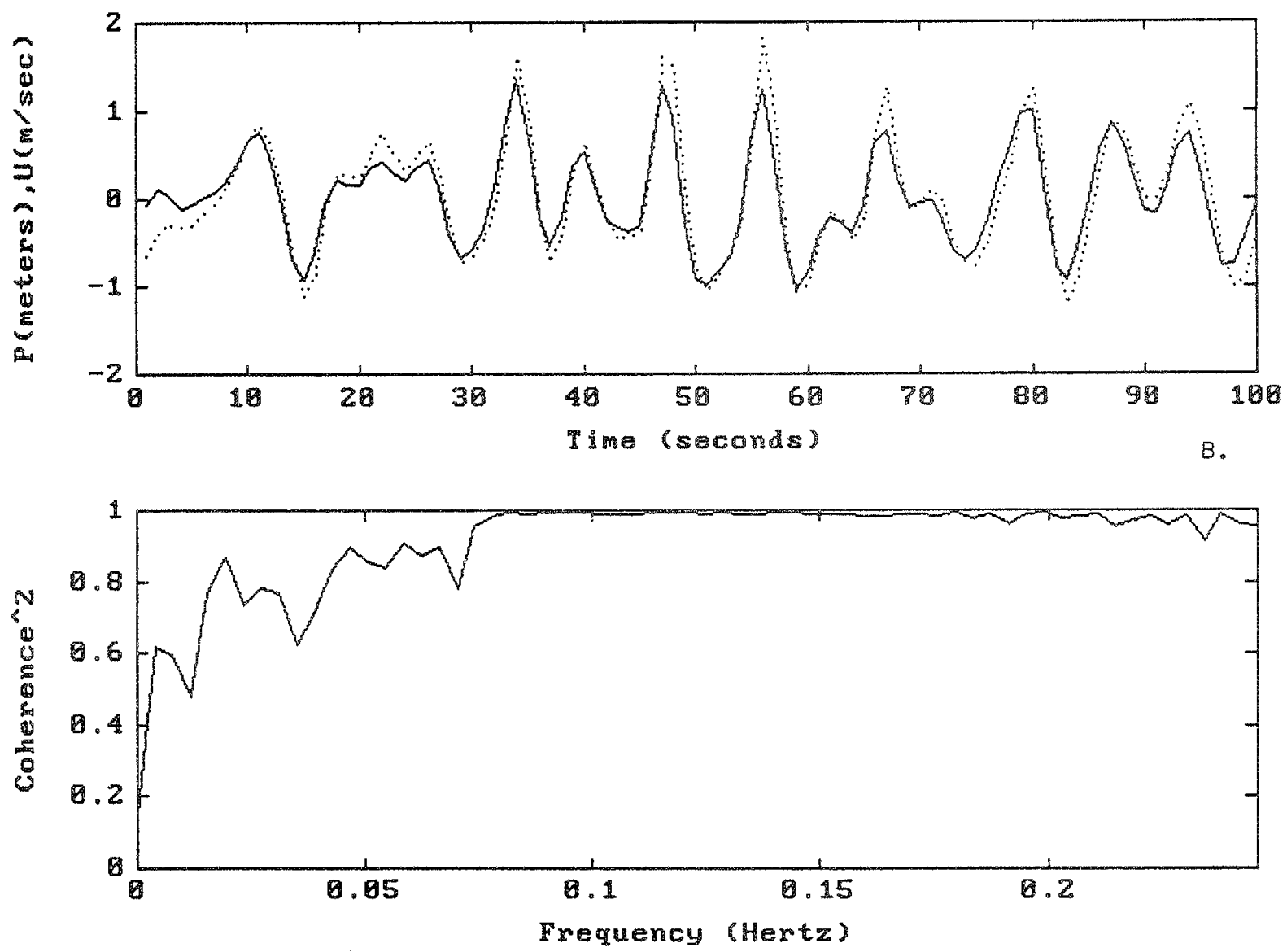

FIG. 7 (a) PRESSURE AND VELOCITY TIME RECORO

(b) COHERENCE SQUARED OF PRESSURE, ONSHORE-OFFSHORE VELOCITY 

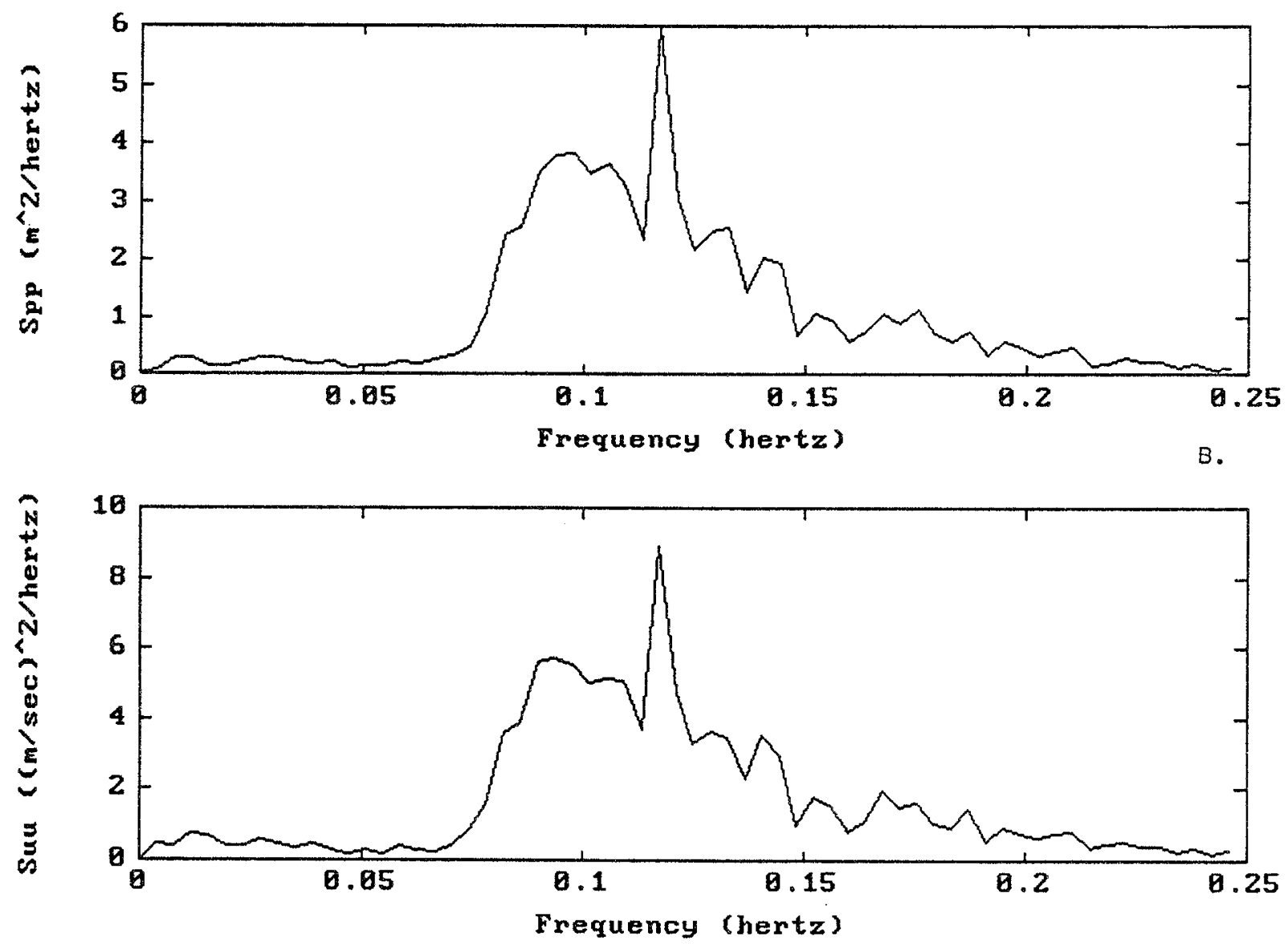

FIG. 8 (a). VARIANCE SPECTRUM OF PRESSURE

(b) VARIANCE SPECTRUM OF ONSHORE-OFFSHORE VELOCITY 

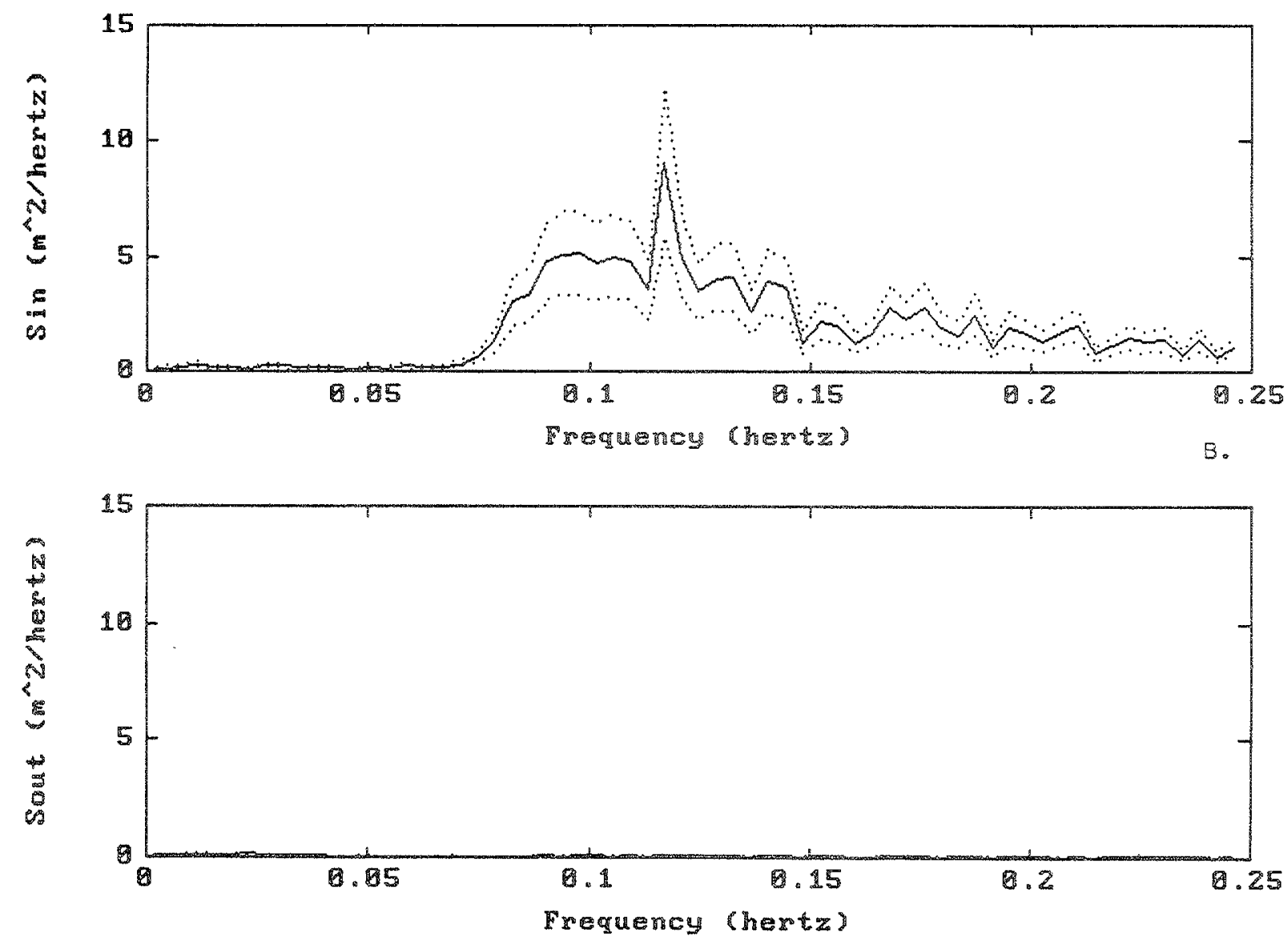

FIG. 9 (a) VARIANCE SPECTRUM OF INCIUENT WAVE TRAIN SURFACE ELEVATION (b) VARIANCE SPECTRUM OF REFLECTED WAVE TRAIN SURFACE ELEVATION 
UUCK $0614,1 \mid$ OCTOBER 1986

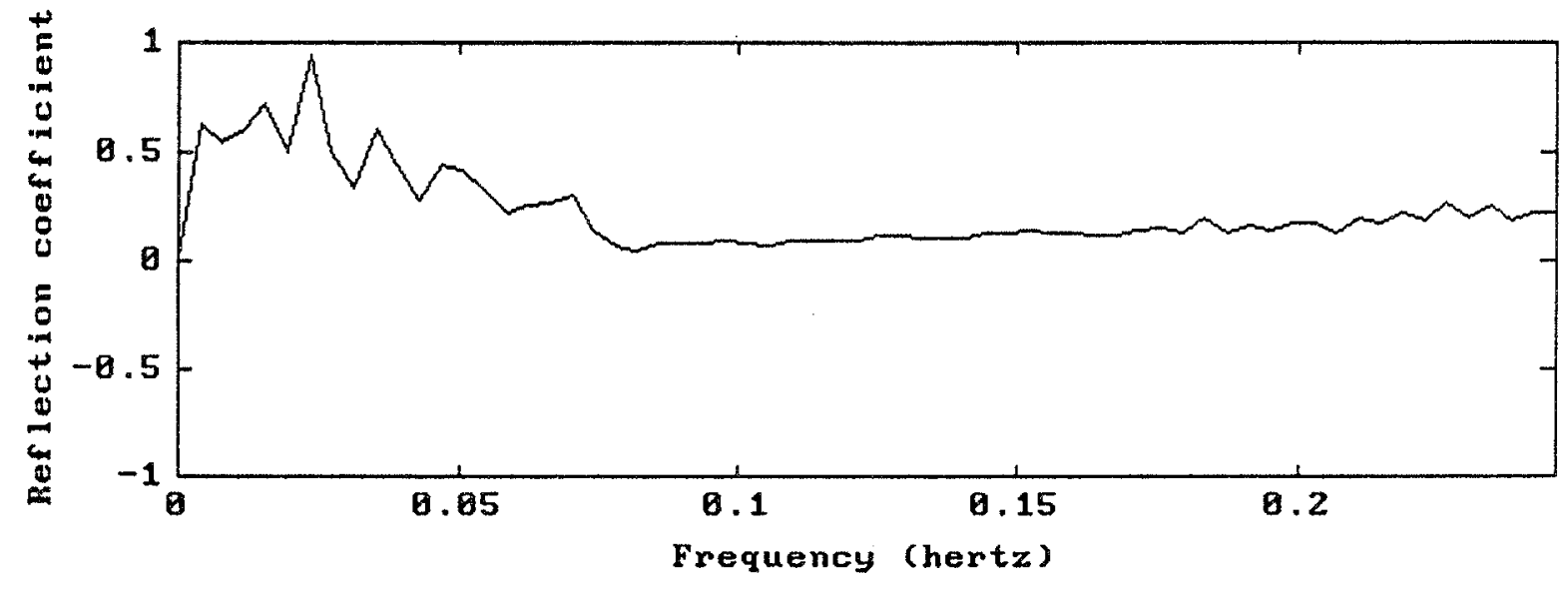

FIG. 10

REFLECTION COEFFICIENT 

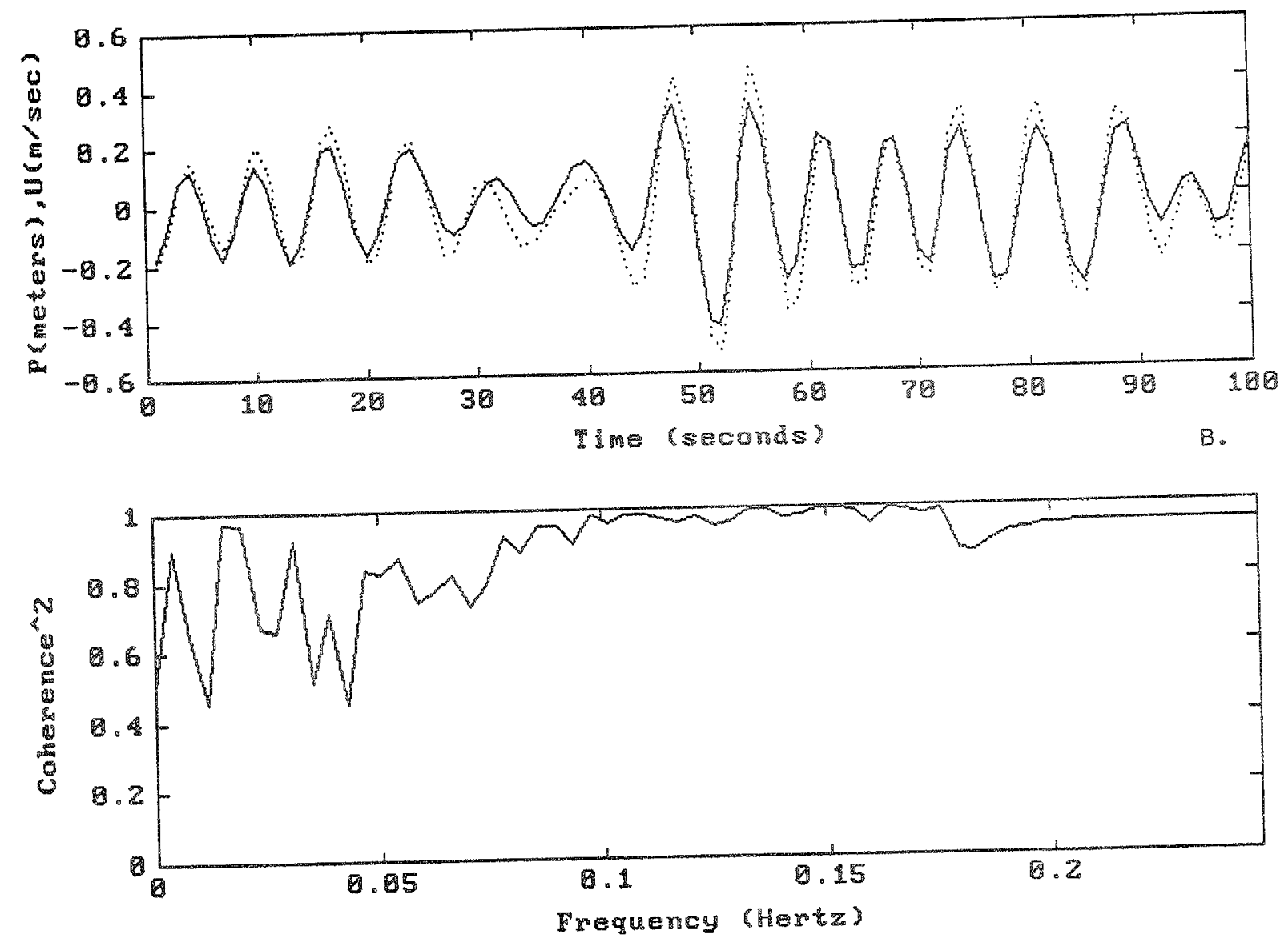

FIG. 11 (a) PRESSURE AND VELOCITY TIME RECORD

(b) COHERENCE SQUARED OF PRESSURE, ONSHORE-OFFSHORE VELOCITY 
OCEAN CITY 0400, 22 MAY 1990

A.

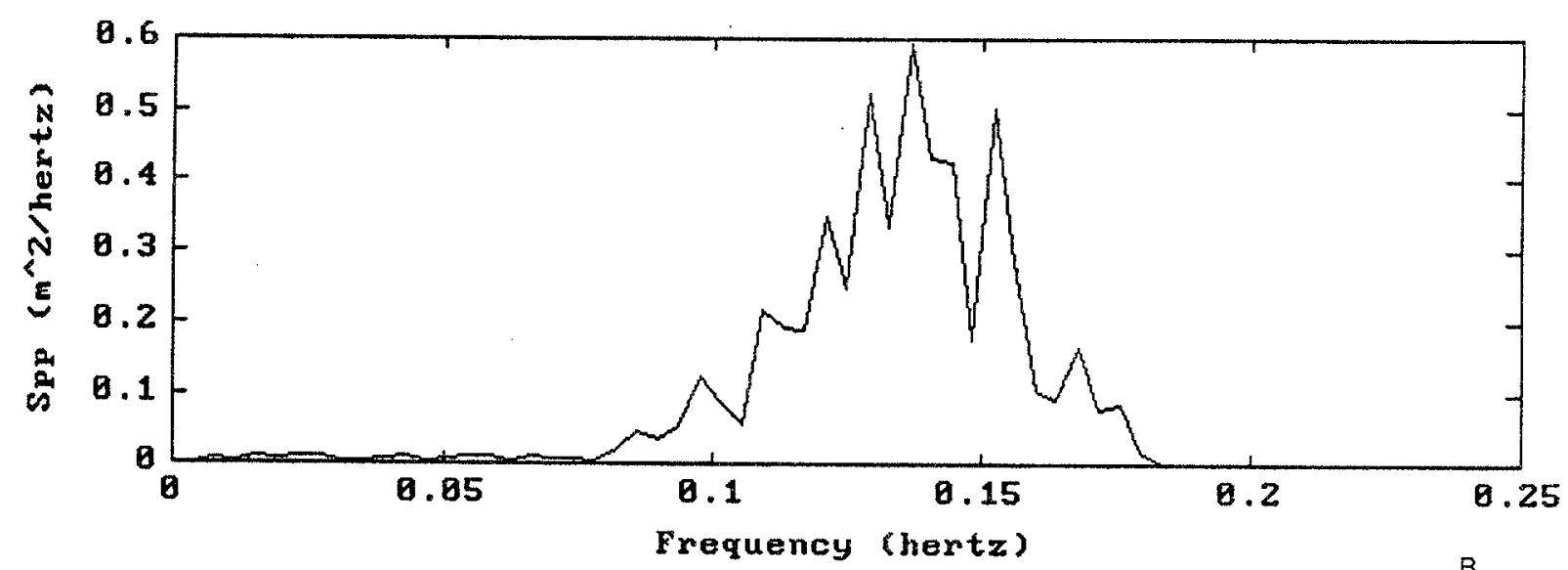

B.

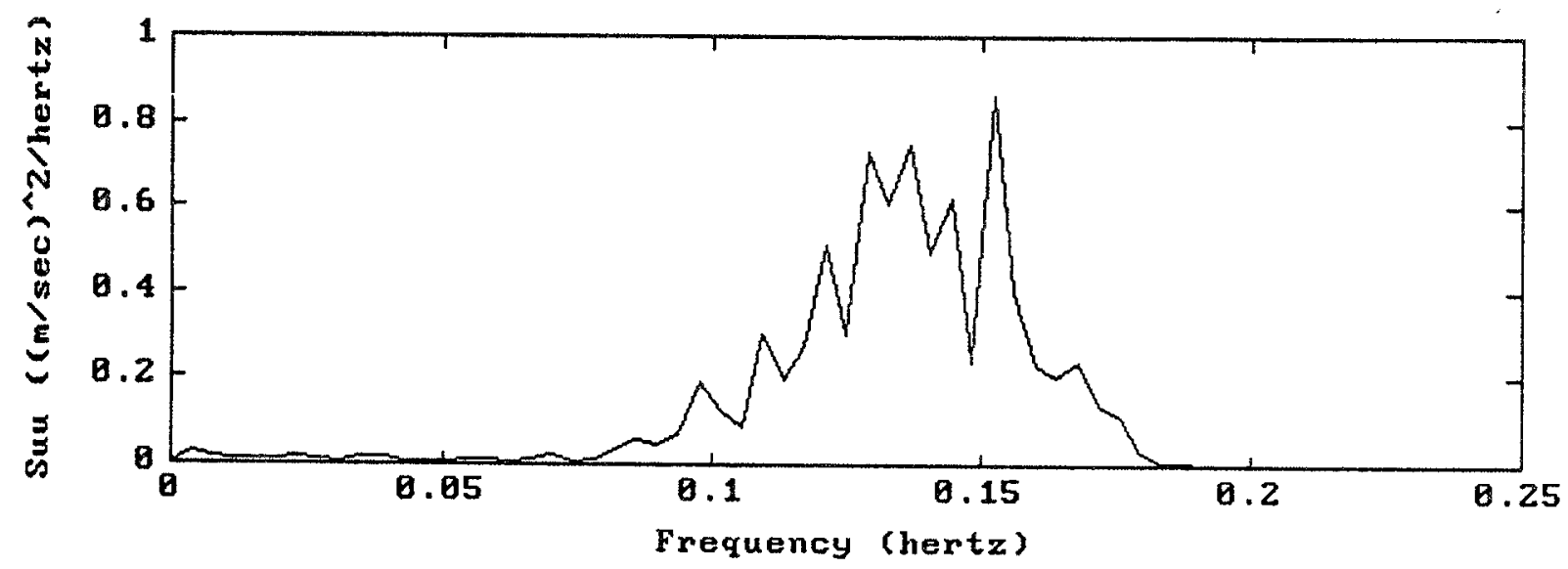

FIG. I2 (a) VARIANCE SPECTRUM OF PRESSURE

(b) VARIANCE SPECTRUM OF ONSHORE-OFFSHORE VELOCITY 

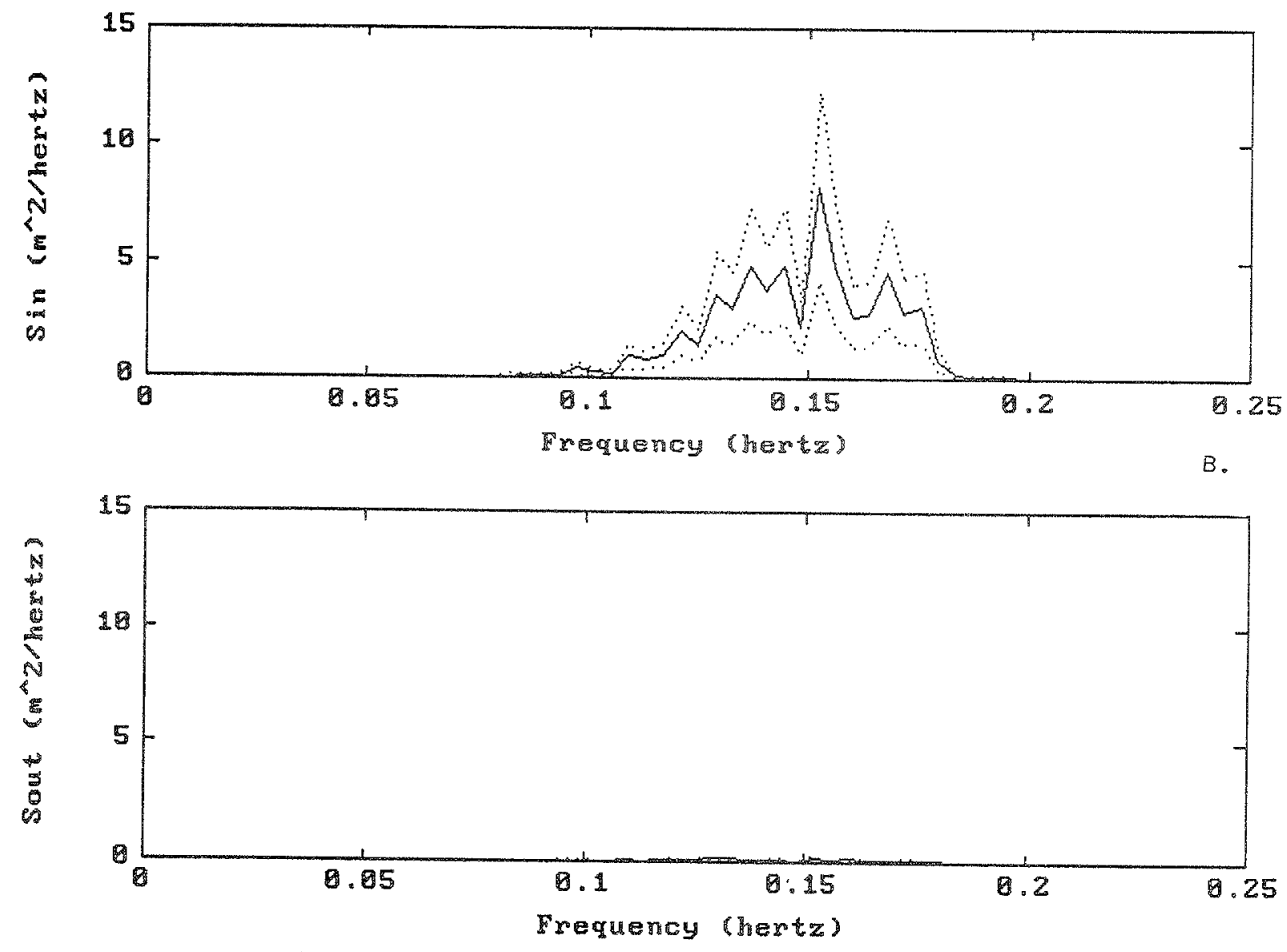

FIG. I3 (a) VARIANCE SPECTRUM OF INCIDENT WAVE TRAIN SURFACE ELEVATION

(b) VARIANCE SPECTRUM OF REFLECTED WAVE TRAIN SURFACE ELEVATION 


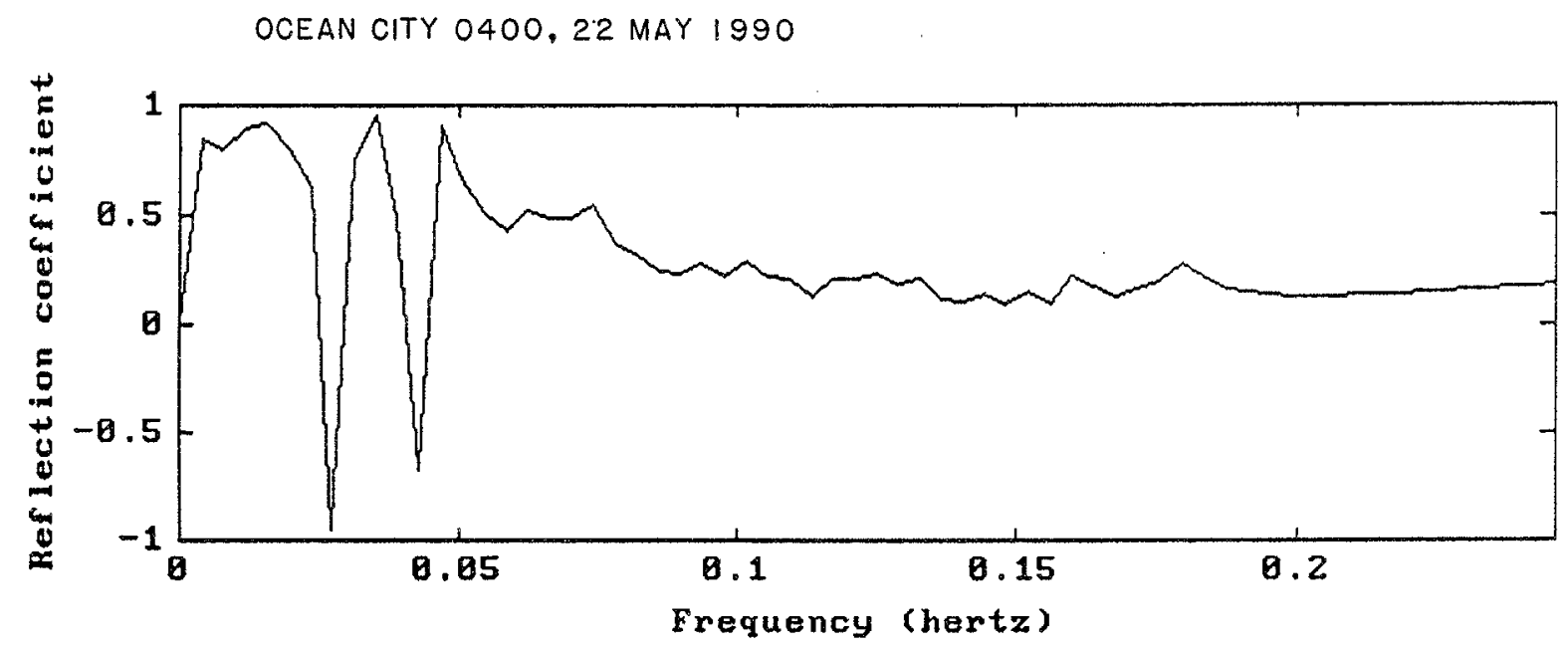

FIG. I 4 REFLECTION COEFFICIENT 

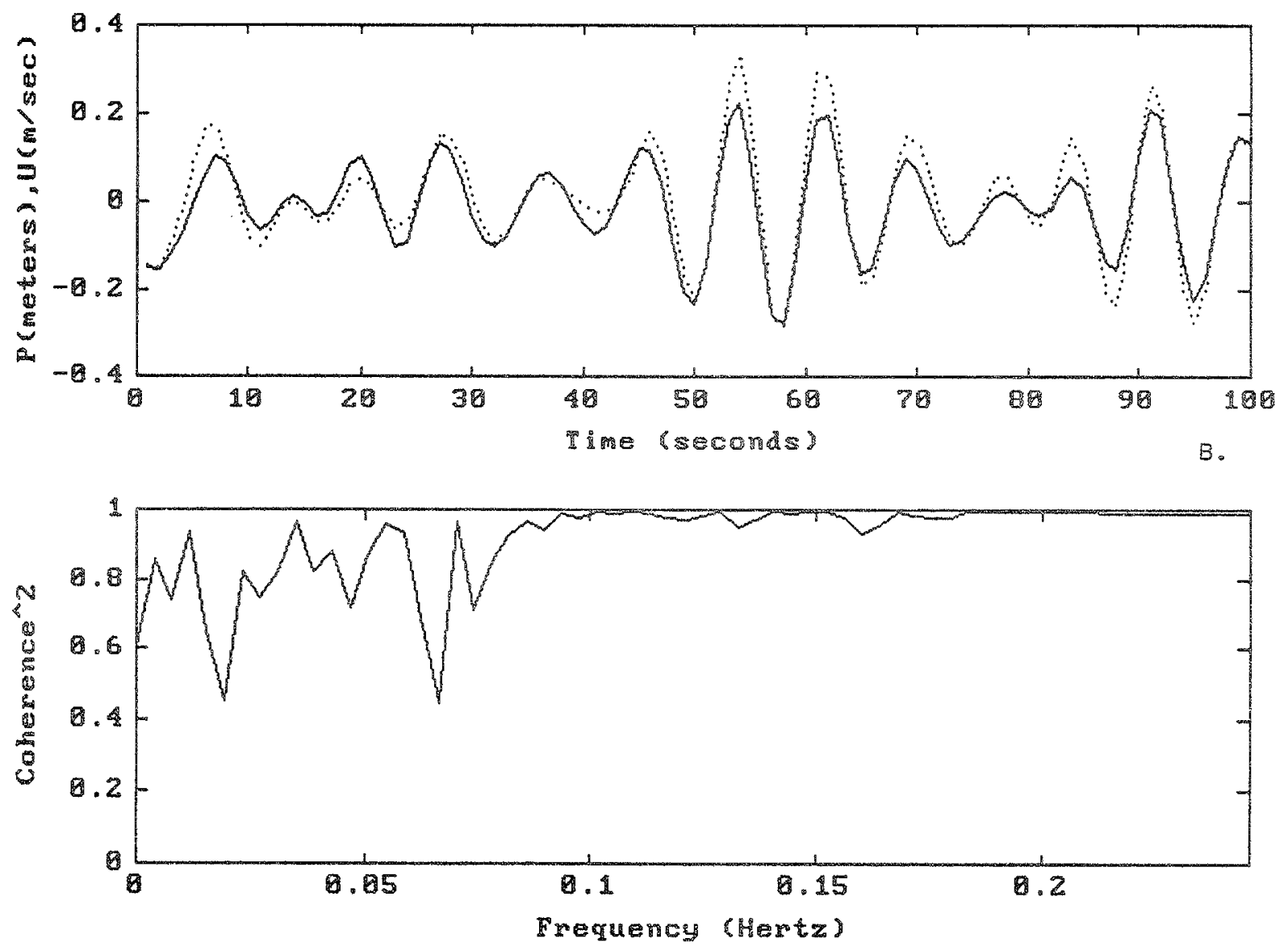

FIG. I 5 (a): PRESSURE AND VELOCITY TIME RECORD

(b) COHERENCE SQUARED OF PRESSURE, ONSHORE-OFFSHORE VELOCITY 

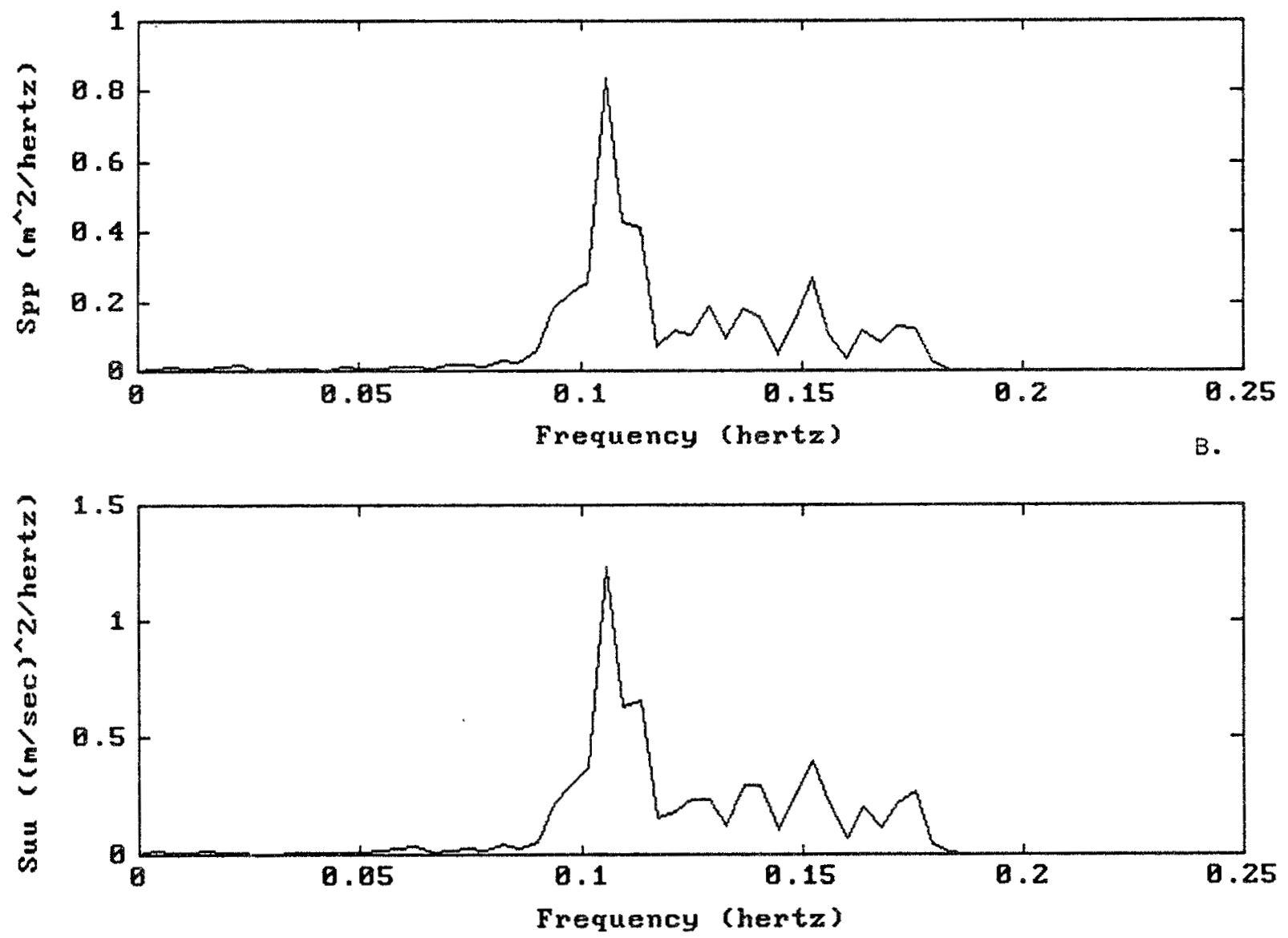

FIG. I6 (a) VARIANCE SPECTRUM OF PRESSURE

(b) VARIANCE SPECTRUM OF ONSHORE-OFFSHORE VELOCITY 

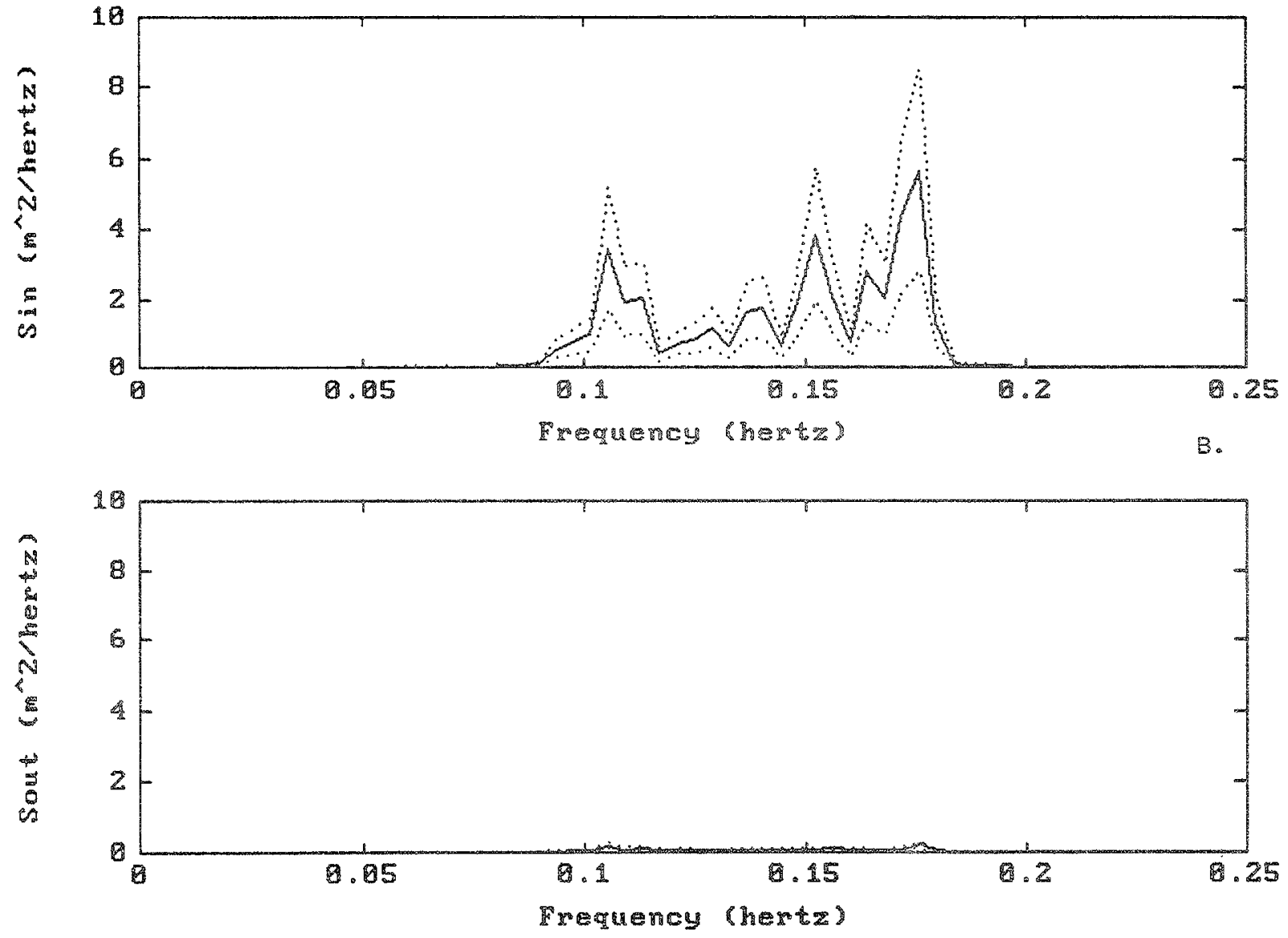

FIG. 17 (a) VARIANCE SPECTRUM OF INCIOENT WAVE TRAIN SURFACE ELEVATION (b) VARIANCE SPECTRUM OF REFLECTED WAVE TRAIN SURFACE ELEVATION 
OCEAN GTY 1600, 22 MAY 1990

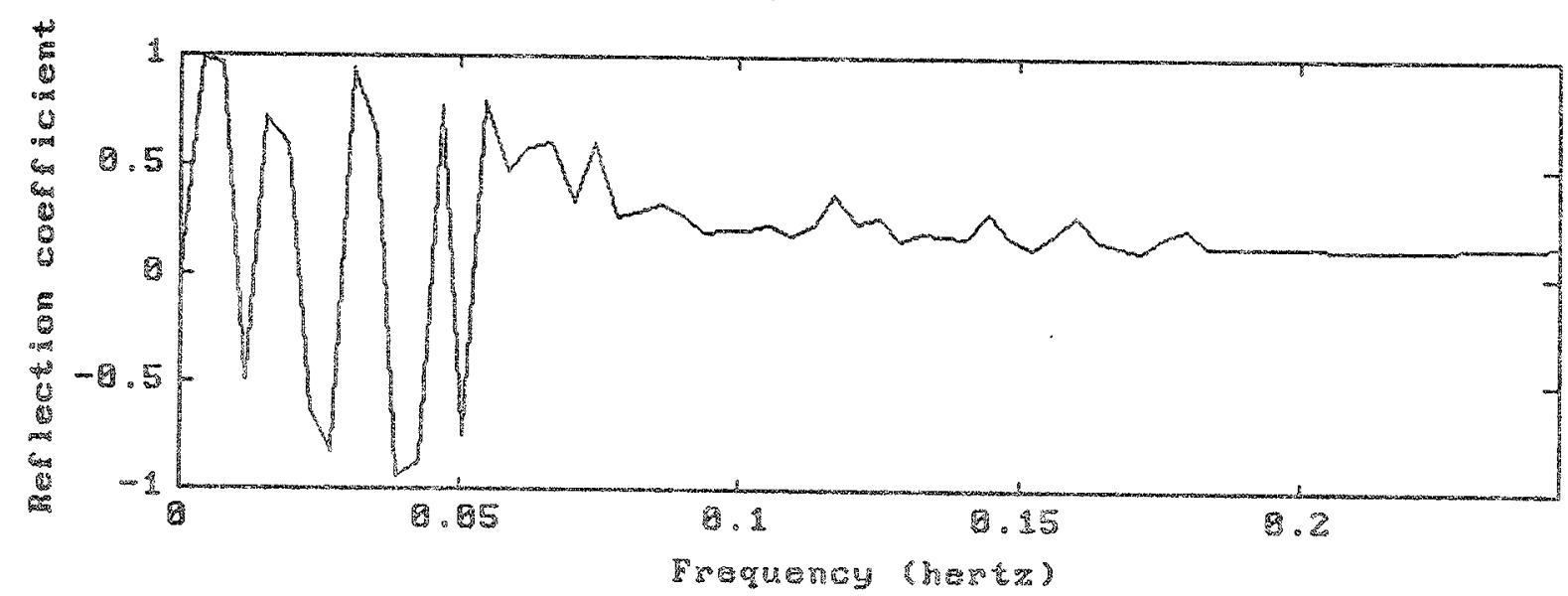

FO. IS REFLETION COEFPIOINT 